\title{
The Pu-U-Am system: An ab initio informed CALPHAD thermodynamic study
}

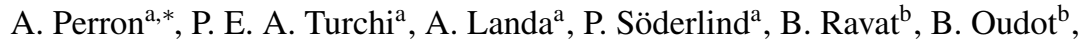 \\ F. Delaunay \\ ${ }^{a}$ Lawrence Livermore National Laboratory, Livermore, CA 94550, USA \\ ${ }^{b}$ CEA-Centre de Valduc, 21120 Is sur Tille, France
}

\begin{abstract}
Phase diagram and thermodynamic properties of the Am-U system, that are experimentally unknown, are calculated using the CALPHAD method with input from $a b$ initio electronic-structure calculations for the fcc and bcc phases. A strong tendency toward phase separation across the whole composition range is predicted. In addition, ab initio informed $\mathrm{Pu}-\mathrm{U}$ and $\mathrm{Am}-\mathrm{Pu}$ thermodynamic assessments are combined to build a $\mathrm{Pu}-$ U-Am thermodynamic database. Regarding the Pu-rich corner of the ternary system, predictions indicate that Am acts as a powerful $\delta$-Pu (fcc) stabilizer. In the U-rich corner, similar predictions are made but to a lesser extent. In both cases, the bcc phase is destabilized and the fcc phase is enhanced. Finally, results and methodology are discussed and compared with previous assessments and guidelines are provided for further experimental studies.
\end{abstract}

\section{Introduction}

The current interest in developing future generations of nuclear reactors, for instance the GEN-IV advanced nuclear reactors [1], entails a better understanding of the thermodynamic properties of actinide alloys. In addition to the various nuclear energy systems technical feasibility (gas-, lead- and sodium-cooled fast reactors, molten salt reactor, supercritical-water-cooled and very-high-temperature reactor systems) and

\footnotetext{
* Corresponding author

Email address: perronlallnl.gov or aurelien.perron.contactagmail.com (A. Perron)
}

Preprint submitted to Journal of ${ }^{B} T_{E} X$ Templates

December 29, 2014 
their associated safety and security requirements, there is a need to characterize, understand, and predict the behavior of their fuels. Because one fuel option for the next generation of actinide burner reactors is a Pu-U-based alloy with an increasing amount of Am with fuel burn up, the ternary Pu-U-Am system is of technological importance.

The Pu-U-Am system was first investigated by Ogawa [2] using the Brewer valence bond model [3]. The model, that allows estimation of the interaction parameters between metal atoms, determined the alloying behavior among actinides ( $\mathrm{U}, \mathrm{Np}, \mathrm{Pu}$ and Am), and the high-temperature constitutions of binary alloys (Fig. 1a-c). However, this (Fig. 1a), the model result is characterized by a liquid miscibility gap with a monotectic invariant line at about $1107^{\circ} \mathrm{C}(1380 \mathrm{~K})$. Ogawa reported that this result seems to be underpinned by experimental works performed by Inoue et al. [4]. Indeed, an attempt to fuse a nearly equimolar mixture of $\mathrm{U}$ and $\mathrm{Am}$ failed, giving an inhomogeneous mass consisting of apparently immiscible phases. It is worth noting that the phase diagram calculated by Ogawa is incomplete, as low-temperature allotropes of both terminal elements were not considered ( $\alpha$-U - orthorhombic_A20; and $\alpha$-Am - dhcp), but that no experimental data are available for this system. As a rule of thumb, a greater solubility of $\mathrm{U}$ in Am than vice versa was predicted. Regarding the Am-Pu system (Fig. 1b), the calculated high-temperature phase diagram gives complete solubility between $\delta$-Pu (fcc) and $\beta$-Am (fcc) and between $\epsilon$-Pu (bcc) and $\gamma$-Am (bcc). Then, the interactions between $\mathrm{Pu}$ and $\mathrm{U}$ at high temperature were calculated for the bcc and liquid phases of the Pu-U system. In spite of some discrepancies observed between the experimental and calculated solidus curves of the Pu-U binary (Fig. 1c), this system was combined with that of the Am-U and Am-Pu to build the ternary Pu-U-Am system (Fig. 1d). Predictions for the ternary Pu-U-Am system were made and the effect of Pu addition to the Am-U poor miscibility was investigated. Ogawa found that both liquid and bcc miscibility gaps close rather rapidly with increasing Pu content. Thus, Pu seems to improve the poor solubility of $\mathrm{Am}$ and $\mathrm{U}$ in the bcc and liquid phases. In addition, Ogawa noted that at about 10 at.\% $\mathrm{Pu}$, which is a probable $\mathrm{Pu}$ concentration in the fuel, the Am solubility in the U-rich region will be less than 10 at. $\%$ at $927^{\circ} \mathrm{C}(1200 \mathrm{~K}$, Fig. 1d). Since the tie-lines run parallel to the Am-U side, Pu will be almost equally partitioned 
between the U- and Am-rich phases [2].

Later on, Kurata published two studies dedicated to the CALPHAD-based (CALamong the $\zeta, \eta$, and $\beta$-Pu phases disagree by $\sim 100^{\circ} \mathrm{C}$ from the experimental value. Ultimately, Kurata gathered the thermodynamic database developed for the binaries to predict isotherms of the ternary Pu-U-Am system (Fig. 2d). The author concluded that although the miscibility between $\mathrm{U}$ and Am is very poor, it is increasing with $\mathrm{Pu}$ 65 content.

As the two previous studies of the Pu-U-Am system were based on incomplete binaries, and thanks to the advancement of $a b$ initio electronic-structure theory, the purpose of the present work is to develop an ab intio informed CALPHAD thermodynamic 
database. Indeed, accurate $a b$ initio calculations have recently proved their efficiency by giving a reliable energetic basis to the thermodynamic CALPHAD re-assessment of the Pu-U (Fig. 3, [19]) and the Am-Pu (Fig. 4, [20]) systems. The development of the present $a b$ intio informed CALPHAD thermodynamic database, that includes the Am-U (re-evaluated), Am-Pu, and $\mathrm{Pu}-\mathrm{U}$ binary systems, will help to predict the phase stability, and thus the properties of the Pu-U-Am system versus composition and temperature changes. Because the experimental determination of phase diagrams on actinide alloys are costly, time-consuming, and challenging, the predictions made for the Pu-U-Am system provide useful guidance for well-chosen experiments. These experiments can furthermore be used to validate and/or refine the present thermodynamic database.

The paper is organized as follows. The thermodynamic models are described in Section 2 while the ab initio calculation details and the resulting output data are reported in Section 3. The Am-U thermodynamic assessment as well as the the $\mathrm{Pu}-\mathrm{U}$ and Am-Pu thermodynamic descriptions are detailed in Section 4, leading to the predicted Pu-U-Am ternary phase diagram. Accompanying discussions and guidelines for further studies are given in Section 5.

\section{Thermodynamic modeling}

The aim of the CALPHAD method is to model the Gibbs energy $[5,6,7]$. This involves the selection of analytical thermodynamic models for the Gibbs energy description of any structure and any phase as a function of chemical composition, tem${ }_{90}$ perature and pressure. In addition, the model parameters must be optimized to best fit the critically selected thermodynamic and phase diagram data as input. Once such functions have been assessed, they are compiled in a thermodynamic database that can be used for computational thermodynamic predictions of multi-component materials. Indeed, the strength of the CALPHAD method lies in the fact that the assessed databases should be self-consistent and thus can be combined to predict the thermodynamic behavior of multi-component systems.

For the unaries, the Gibbs energy function for the element $\mathrm{X}(\mathrm{X}=\mathrm{Am}, \mathrm{Pu}, \mathrm{U})$ in the 
pure phase $\phi$ is (for simplicity, the pressure dependence and the magnetic contribution are not shown here) generally written as:

$$
{ }^{0} G_{X}^{\phi}=G_{X}^{\phi}-H_{X}^{S E R}=a+b T+c T \ln T+d T^{2}+e T^{3}+f T^{-1}+g_{n} T^{n}
$$

where $H_{X}^{S E R}$ is the molar enthalpy of element $\mathrm{X}$, at $298.15 \mathrm{~K}$ and $10^{5} \mathrm{~Pa}$, in its standard element reference (SER) state, i.e., $\alpha$-Am (double hexagonal close-packed, dhcp), $\alpha$-Pu (simple monoclinic) and $\alpha-\mathrm{U}$ (orthorhombic_A20), and T is the absolute temperature. Note that the power series used to describe the Gibbs energy for pure elements comes from initial experimental measurements of heat capacity and from classical thermodynamics. Indeed, the temperature dependance of the heat capacity $\left(\mathrm{C}_{P}\right)$ was initially described by the following empirical equation:

$$
C_{P}=x+y T-\left(z / T^{2}\right)
$$

Regarding the relations of classical thermodynamics:

$$
\begin{aligned}
C_{P} & =\left(\frac{d H}{d T}\right)_{P}=-T\left(\frac{d^{2} G}{d T^{2}}\right)_{P} \\
& =-c-2 d T-6 e T^{2}-2 f T^{-2}-\sum n(n-1) g T^{n-1} \\
S & =\int_{0}^{T}\left(\frac{C_{P}}{T}\right) d T=\left(\frac{-d G}{d T}\right)_{P} \\
& =-b-c(1+\ln T)-2 d T-3 e T^{2}+f T^{-2}-\sum n g T^{n-1} \\
H & =\int_{298}^{T} C_{P} d T=G+T S=G-T\left(\frac{d G}{d T}\right)_{P} \\
& =a-c T-d T^{2}-2 e T^{3}+2 f T^{-1}-\sum(n-1) g T^{n}
\end{aligned}
$$

the various parameters of Eq. 1 can be optimized. In the present study, the empirical parameters ( $a$ to $g$ in Eq. 1) are taken from the data compiled by Dinsdale [21]. In the case of pure Am, the two allotropic transformations, i.e. $\alpha$-Am (dhcp) $\rightarrow \beta$ $\mathrm{Am}$ (fcc) $\rightarrow \gamma-\mathrm{Am}$ (bcc), are well calculated at 769 and $1077^{\circ} \mathrm{C}$, before melting at $1175^{\circ} \mathrm{C}$. Regarding the pure $\mathrm{Pu}$, the six transitions, $\alpha$-Pu (simple monoclinic) $\rightarrow \beta$ $\mathrm{Pu}$ (body-centered monoclinic) $\rightarrow \gamma$-Pu (face-centered orthorhombic) $\rightarrow \delta$-Pu (fcc) 
$\rightarrow \delta^{\prime}-\mathrm{Pu}$ (body-centered tetragonal) $\rightarrow \epsilon-\mathrm{Pu}$ (bcc) $\rightarrow$ Liquid, are well described with transition temperatures of $124,215,320,463,483$, and $640^{\circ} \mathrm{C}$, respectively. Finally, the $\alpha$-U (orthorhombic_A20) $\rightarrow \beta$-U (tetragonal) $\rightarrow \gamma$-U (bcc) $\rightarrow$ Liquid transformations, are also well determined with transition temperatures of 669,776 and $1135^{\circ} \mathrm{C}$, respectively.

For stoichiometric compounds, the Gibbs energy can be written in its simplest form as:

$$
G^{A_{X} B_{Y} \cdots}=\sum_{I=A, B \cdots} c_{I}{ }^{0} G_{I}^{\phi_{I}}+a+b T
$$

where a $+\mathrm{bT}$ represents the Gibbs energy of formation $\Delta G^{f}$ of a specific compound formed from the pure elements considered in their states $\phi_{I}$ with compositions $c_{I}$ (equivalent to the stoechiometric coefficients). These states can be a given phase (structure), identical to the one of the compound, the SER state of each element (generally accepted), or any other reference states. The model parameters $a$ and $b$ represent the enthalpy and the entropy of formation of the compound, respectively [22]. In fact, the entropy of mixing for an ideal solution presented below for multi-component solution phases (Eq. 7) is equal to 0 for stoechiometic compounds, since there is no random mixing [23].

For multi-component solution phases, it has proven useful to distinguish three contributions from the concentration dependence to the Gibbs energy of a phase:

$$
G_{m}^{\phi}={ }^{0} G^{\phi}+{ }^{i d} G^{\phi}+{ }^{x s} G^{\phi}
$$

where ${ }^{0} G^{\phi}$ is the contribution from the mechanical mixing of the pure components, ${ }^{i d} G^{\phi}$ is the ideal mixing contribution (that corresponds to the entropy of mixing for an ideal solution), and ${ }^{x s} G^{\phi}$ is the excess Gibbs energy of mixing due to non-ideal interactions (the so-called excess term). For a multi-component solution in a particular phase $\phi$ described with a single sublattice model, the three contributions to the total Gibbs energy reduce to:

$$
\begin{gathered}
{ }^{0} G^{\phi}=\sum_{I} c_{I}{ }^{0} G_{I}^{\phi} \\
{ }^{i d} G^{\phi}=R T \sum_{I} c_{I} \ln c_{I}
\end{gathered}
$$




$$
{ }^{x s} G^{\phi}=\sum_{I} \sum_{J>I} c_{I} c_{J} \sum_{k=0}^{p}{ }^{k} L_{I, J}^{\phi}\left(c_{I}-c_{J}\right)^{k}
$$

where $\mathrm{R}$ is the gas constant. For a binary system (Am-U, Pu-U, Am-Pu), the total Gibbs energy can be rewritten as:

$$
\begin{aligned}
G_{I, J}^{\phi} & =c_{I}{ }^{0} G_{I}^{\phi}+c_{J}{ }^{0} G_{J}^{\phi} \\
& +R T\left[c_{I} \ln c_{I}+c_{J} \ln c_{J}\right] \\
& +c_{I} c_{J} \sum_{k=0}^{p}{ }^{k} L_{I, J}^{\phi}\left(c_{I}-c_{J}\right)^{k}
\end{aligned}
$$

where the excess molar Gibbs energy of mixing is expressed by a Redlich-Kister (RK) polynomial expansion (the sum of the terms $\left(c_{I}-c_{J}\right)^{k}$ is the so-called Redlich-Kister polynomial) $[23,24]$. In these expressions, $c_{I}$ is the composition of the alloy in species $I$, and ${ }^{k} L_{I, J}^{\phi}$ is the $k^{t h}$-order ( $k \leq 2$ in the present assessment) binary interaction parameter, between species $I$ and $J$, usually expressed as a first-order polynomial in temperature:

$$
{ }^{k} L_{I, J}^{\phi}={ }^{k} a_{I, J}^{\phi}+{ }^{k} b_{I, J}^{\phi} T
$$

For a ternary system (Pu-U-Am), the previous equations (Eq. 8-10) give:

$$
\begin{aligned}
G_{I, J, K}^{\phi} & =c_{I}{ }^{0} G_{I}^{\phi}+c_{J}{ }^{0} G_{J}^{\phi}+c_{K}{ }^{0} G_{K}^{\phi} \\
& +R T\left[c_{I} \ln c_{I}+c_{J} \ln c_{J}+c_{K} \ln c_{K}\right] \\
& +c_{I} c_{J} \sum_{k=0}^{p}{ }^{k} L_{I, J}^{\phi}\left(c_{I}-c_{J}\right)^{k}+c_{I} c_{K} \sum_{k=0}^{p}{ }^{k} L_{I, K}^{\phi}\left(c_{I}-c_{K}\right)^{k} \\
& +c_{J} c_{K} \sum_{k=0}^{p}{ }^{k} L_{J, K}^{\phi}\left(c_{J}-c_{K}\right)^{k}
\end{aligned}
$$

Note that in Eq. 13, the Gibbs energy of a ternary- or higher-order solution phase is determined by extrapolation of the binary energies using Muggianu's method [25]. If necessary, a ternary term $c_{I} c_{J} c_{K} L_{I, J, K}^{\phi}$ can be added in order to describe the contribution of three-element interactions to the Gibbs energy [23]. Even if they are not used in the present study, more models based on multi-sublattices also exist for ordered phases having a range of solubility or exhibiting an order/disorder transformation $[5,6,7,23]$. 


\section{Ab initio method and results}

CALPHAD is an iterative method, founded on the equations of the the previous

125 section, that adjusts the parameters describing the Gibbs energies of various phases in a system in order to construct a phase diagram that best fits the available thermodynamic and phase diagram data for the system. It is worth noting that the process of parameter optimization and error minimization involved in the CALPHAD method is an inverse problem with infinite degrees of freedom [26]. Thus, many possible combinations of values of user-defined parameters could produce phase boundaries and diagrams that perfectly coincide. Therefore, the use of $a b$ initio energetics during the CALPHAD assessment constrains the optimization process, adds new input (for instance, the heat of formation) when experimental data are sparse or missing, and validates the resulting thermodynamic database not only from a diagrammatic representation, but also from a reliable energetic basis.

Theoretical studies of actinide-bearing systems are challenging for many reasons. First and foremost, the $f$ electrons can in some systems correlate strongly that limits the applicability of methods where strong electron correlations are not explicitly accounted for. Examples of such systems include (4f) rare-earth metals [27] and (5f) actinide oxides [28]. Fortunately, the energetics of the actinide metals and their metallic fuel alloys is often very well described by density-functional-theory (DFT) parameter-free calculations. The early actinide metals (Th-Np) show relatively weak electron correlation [29] while for Pu and Am it is stronger but energetics can still be reasonably modeled by a DFT approach $[30,31]$. Another challenging aspect of these heavy materials is the need to account for all relativistic effects, including spin-orbit interaction. Previous DFT studies on the bcc and fcc phases for actinide alloys have revealed that a fully-relativistic treatment is necessary for an accurate determination of the energetics of all Pu-based alloys [20, 32, 33, 34]. Because relativistic effects cannot be ignored, the exact muffin-tin orbital (EMTO) electronic-structure method has been utilized here that applies a fully relativistic (FR) Green's function technique (based on the improved screened Korringa-Kohn-Rostoker method). EMTO is combined with the coherent potential approximation (CPA) for the calculation of the total energy of 
chemically random alloys. Pertinent details about the ab initio methodology (EMTOCPA) used in the present study are described in $[32,33,35]$. The calculated heats of formation of the bcc phase (Am-U, Pu-U and Am-Pu systems) as well as the fcc phase (Am- $\mathrm{U}$ and $\mathrm{Am}-\mathrm{Pu}$ ) are presented in Fig. 5a. These values are very interesting because at $\mathrm{T}=0 \mathrm{~K}$, the heats of formation of bcc and fcc alloys resulting from $a b$ initio calculations correspond to the T-independent terms that enter the expression for the excess Gibbs energy of random solution (i.e., the coefficients ${ }^{k} a_{I, J}^{\phi}$ in Eq. 12). This ab initio input constrains the present CALPHAD thermodynamic assessment by only having to determine the T-dependent terms (i.e., the coefficients ${ }^{k} b_{I, J}^{\phi}$ in Eq. 12), thus making it more trustworthy.

Technically, the ab initio calculated heats of formation of the bcc and fcc solution phases (symbols in Fig. 5a), which are equal to the excess Gibbs energy of mixing at $\mathrm{T}=0 \mathrm{~K}$, can be fitted by a RK polynomial of first order (subregular-solution model) using Eq. 10, i.e.:

$$
{ }^{x s} G^{\phi}(0 K)=c_{I} c_{J}\left({ }^{0} L_{I, J}^{\phi}+{ }^{1} L_{I, J}^{\phi}\left(c_{I}-c_{J}\right)\right)
$$

With $\phi=\mathrm{bcc}$ or fcc, and using $c_{I}=c$ and $c_{J}=1-c$, Eq. 14 gives:

$$
{ }^{x s} G^{\phi}(0 K)=c(1-c)\left[{ }^{0} L_{I, J}^{\phi}+{ }^{1} L_{I, J}^{\phi}(2 c-1)\right]=c(1-c) L_{I, J}^{\phi}
$$

In the present study, the RK description of the ab initio predicted excess Gibbs free energy at $0 \mathrm{~K}$ (in J/mol), resulting from the curve fitting of Fig. $5 \mathrm{a}$, is given by:

$$
\begin{gathered}
L_{A m, U}^{f c c}=+54442+23338(2 c-1) \\
L_{A m, U}^{b c c}=+82254+35866(2 c-1) \\
L_{A m, P u}^{f c c}=+21157-1518(2 c-1) \\
L_{A m, P u}^{b c c}=+25855-4906(2 c-1) \\
L_{P u, U}^{b c c}=-4808-1389(2 c-1)
\end{gathered}
$$

With $c=c_{A m}$ for $L_{A m, U}^{\phi}$ and $L_{A m, P u}^{\phi}$, and $c=c_{P u}$ for $L_{P u, U}^{\phi}$. Note that the values for the Pu-U and Am-Pu systems have already been used successfully in [19] and [20]. 
Ultimately, the values calculated for the Am-Np system are also presented to study the trend of the Am-X series with $\mathrm{X}=\mathrm{U}, \mathrm{Np}, \mathrm{Pu}$.

$$
L_{A m, N p}^{b c c}=+85560-6043(2 c-1)
$$

The metastable miscibility gaps calculated using Eq. 11 and based only on the T-independent RK interaction parameters determined from Eq. 16-19 are plotted in 165 Fig. $5 \mathrm{~b}$ and will be discussed in Section 5.

\section{CALPHAD Assessments}

\subsection{The underlying binaries}

The strength of the CALPHAD method lies in the prediction of the thermodynamic behavior of multi-component systems. However, the computation of thermodynamic and phase diagram properties of the ternary Pu-U-Am system requires a critical evaluation and assessment of all underlying binary systems (Am-U, Pu-U and Am-Pu). The crystal structures data of the pure elements and of the known solid solutions, taken from $[36,37,38,39]$, are reported in Table 1 . Note that here the structure of pure elements $(\gamma$-Am, $\gamma$-U...) and the alloy phases with the same structure (for instance, the $\epsilon$-Pu 175 solid solution) have the same notation for the sake of clarity. The Gibbs energies of the pure stable phases $\left(\alpha-, \beta-, \gamma\right.$ - and liquid $\mathrm{Am} / \mathrm{U}$, and $\alpha-, \beta-, \gamma-, \delta-, \delta^{\prime}-, \epsilon$ - and liquid $\mathrm{Pu}$ ) are given by Dinsdale [21]. In addition, the Gibbs energies of the pure elements in metastable or unstable phases, that are not provided by the SGTE database, are given in Table 2. The Gibbs energies of Am for $\alpha-, \beta-, \gamma$, and $\delta^{\prime}-\mathrm{Pu}$ phases [9], of Pu for $\alpha$-Am [20], of Pu for $\alpha-, \beta-\mathrm{U}$, and of $\mathrm{U}$ for $\beta$-Am, $\beta-, \gamma-, \delta$-, $\delta^{\prime}-\mathrm{Pu}$ [40] phases have been accounted for.

As already mentioned, there are almost no data on the Am-U system. However, based on the two previous studies (Fig. 1a, Fig. 2a) [2, 9], the solubility of Am in $\alpha$-, $\beta-\mathrm{U}$ and of $\mathrm{U}$ in $\alpha$-Am is assumed to be negligible. Thus, the Gibbs energy functions 185 related to these phases $\left(G_{A m, U}^{\alpha-U}, G_{A m, U}^{\beta-U}, G_{A m, U}^{\alpha-A m}\right)$ are not taken into account (Eq. 11), and the corresponding lattice stabilities $\left({ }^{0} G_{A m}^{\alpha-U},{ }^{0} G_{A m}^{\beta-U},{ }^{0} G_{U}^{\alpha-A m}\right)$ have no value in Table 2. Thanks to the ab initio calculations (Fig. 5a) and the use of Eq. 15, the 
T-independent terms of the RK interaction parameters are evaluated (Eq. 16) for the fcc and bcc phases of the Am-U system (reported in Table 3). Because of the lack of experimental data, and similarly to Ogawa's and Kurata's parameter assessments, no T-dependent terms are assessed in the present study. However, the ${ }^{0} L_{A m, P u}^{\text {Liquid }} \mathrm{RK}$ parameter are optimized to form a miscibility gap and to avoid any inverted miscibility gap or any re-entrant fcc or bcc phases at high temperature (when plotting Liquid + fcc or Liquid + bcc metastable phase diagrams). The resulting Am-U phase diagram is presented in Fig. 6. The top of the liquid miscibility gap, located at $2132^{\circ} \mathrm{C}$, is between the Ogawa's $\left(1330^{\circ} \mathrm{C}\right)$ and Kurata's $\left(2734^{\circ} \mathrm{C}\right)$ predictions. However, the width of the present miscibility gap (stable between 4.2 and 95.8 at.\% $\mathrm{U}$ ) is much closer to the previous CALPHAD assessment (stable between 1.8 and 98.2 at.\% U) [9] compared with the Brewer's based model (stable between 35 and 80 at.\% U) [2]. From high to low temperature, the phase domains are similar - Liquid, $\operatorname{Liquid}_{1}+\operatorname{Liquid}_{2}, \mathrm{bcc}+\operatorname{Liquid}_{\text {, }}$ $\mathrm{bcc}_{1}+\mathrm{bcc}_{2}, \mathrm{fcc}+\mathrm{bcc}-$ then, the Ogawa's version differs because the $\alpha$-Am and $\alpha$-U low-temperature phases were not considered. The present assessment is more similar to the one of Kurata with no solubility of $U$ in Am phases and a very poor solubility of Am in $\gamma-U$ (bcc). Indeed, the maximum solubility of Am calculated in $\gamma-U$ (bcc) is equal to 1.6 at.\% for both present and Kurata's CALPHAD assessments, and is equal to 10 at.\% in [2]. In addition, the present assessment exhibits no solubility of $U$ in $\beta$ Am (fcc) and $\gamma$-Am (bcc), which is close to the 0.7 at.\% $\mathrm{U}$ (fcc) and 1.6 at.\% $\mathrm{U}$ (bcc) maximum solubility calculated by Kurata, and far from the first predictions of Ogawa (10 at.\% $\mathrm{U}$ (fcc) and 23 at.\% $\mathrm{U}(\mathrm{bcc})$ ). On the contrary to the first study of Ogawa [2], no preferential solubility of $U$ in Am than vice versa is predicted. However, our assessment - resulting directly from a reliable energetic basis - seems to be supported by results obtained by Kurata on a U-10 at.\% Am alloy [12]. After these experiments, Kurata assumed that the mutual solubility for both $U$ and Am was smaller than 1 at.\% each.

The $\mathrm{Pu}-\mathrm{U}$ phase diagram has been successfully re-assessed in the entire range of alloy composition and temperature (Fig. 3) by recasting the bcc phase $(\gamma-\mathrm{U}, \epsilon-\mathrm{Pu}) a b$ initio energetics (Fig. 5a) in the CALPHAD framework [19]. This phase diagram is characterized by a continuous bcc solid solution across the entire composition range, 
and by two complex $\eta$ and $\zeta$ phases. However, the authors noted that experimental data are needed to characterize crystallography, phase stability and thermodynamics properties of these complex phases. The lattice stabilities of $\mathrm{Pu}$ for $\alpha-\beta-\mathrm{U}$, of $\mathrm{U}$ for $\beta-, \gamma-, \delta-, \delta^{\prime}-\mathrm{Pu}$, and for the $\eta$ and $\zeta$ phases are reported in Table 2 . Note that the solubility of $\mathrm{U}$ in $\alpha-\mathrm{Pu}\left(G_{P u, U}^{\alpha-P u}\right)$ has been neglected, and thus no value of ${ }^{0} G_{U}^{\alpha-P u}$ is given in Table 2. The assessed RK interaction parameters are given in Table 3.

As for the Am-Pu system, the thermodynamic properties and the phase diagram have already been re-assessed with input from $a b$ initio electronic-structure calculations [20]. The heats of formation calculated at $\mathrm{T}=0 \mathrm{~K}$ for the fcc and bcc phases and used during the assessment are also plotted in Fig. 5a. The authors pointed out that, because of the limited availability of experimental data for this binary system, two phase diagrams can be proposed as functions of the relative stability of the bcc $(\gamma-\mathrm{Am}, \epsilon-\mathrm{Pu})$ at high temperature (Fig. 4). The final assessed phase diagram (Fig. 4a) accounts for the existence of a high-temperature bcc solid solution - as expected by Ogawa in [2] (Fig. 1b) - and is in accordance with the most recent experimental findings of Shushakov et al. [41]. However, by substituting the ${ }^{0} L_{A m, P u}^{b c c}$ of Eq. 17 by:

$$
L_{A m, P u}^{b c c}=(+25855+2.5084 T)+(-4906+0.3074 T)(2 c-1)
$$
to the one predicted by Kurata (Fig. 2b) [9] and recently by Gotcu-Freis et al. [42], which are in agreement with the experiments of Ellinger et al. published in 1966 [13]. Indeed, by making the bcc phase less stable - the positive contribution amounts to a maximum of $+800 \mathrm{~J} / \mathrm{mol}$ at $1000^{\circ} \mathrm{C}$ and 47 at. $\% \mathrm{Pu}$, which is only $10 \%$ of the total excess Gibbs energy of the bcc phase [20] - two peritectic reactions occur at the Am- and Pu-rich edges of the phase diagram, limiting the bcc phase solid solution to theses edges (Fig. 4b). This result sheds light on the extreme sensitivity of the high-temperature part of the $\mathrm{Am}-\mathrm{Pu}$ phase diagram to the thermodynamic data, and hence to the purity of the samples. Finally, both phase diagrams presented in Fig. 4 present a two-phase region at low temperature $(\alpha-\mathrm{Am}+\alpha$-Pu) which differs from the fcc-based solid solution calculated by Kurata (Fig. 2b). It is worth pointing out that, 
for the assessment of Kurata, a tendency towards order is assumed for fcc (negative contribution to the enthalpy of mixing for ${ }^{0} L_{A m, P u}^{f c c}$ ) whereas a tendency towards phase separation is considered for bcc (positive contribution to the enthalpy of mixing for ${ }^{250}{ }^{0} L_{A m, P u}^{b c c}$, Table 3). In general, chemical trends are unlikely structure dependent, at least for the simple known structures (bcc, fcc, and hcp), as confirmed by our ab initio results for the $\mathrm{X}-\mathrm{Am}$ (with $\mathrm{X}=\mathrm{U}, \mathrm{Pu}$ ) binaries (Fig. 5a). Hence the assumptions made by Kurata are highly questionable.

\section{2. $P u-U-A m$ predictions}

Predictions of phase stability versus temperature and composition can be made using the RK interaction parameters given in Table 3. In addition to the parameters optimized for the binary systems, new parameters have to be taken into account to describe the interaction between two elements in the metastable host lattice of a third one. For instance, as the $\beta$-Pu phase allows the solubility of both Am and U elements,

${ }_{260}$ i.e. the $L_{A m, P u}^{\beta-P u}$ and $L_{P u, U}^{\beta-P u}$ parameters have been assessed, the $L_{A m, U}^{\beta-P u}$ parameter must be estimated. If not, the Gibbs energy of the $\beta$-Pu phase only composed of the Am and U elements will be only based on the ${ }^{0} G_{A m}^{\beta-P u}$ and ${ }^{0} G_{U}^{\beta-P u}$ lattice stabilities (Eq. 8) plus the ideal mixing entropy (Eq. 9), and can lead to the wrong re-appearance of this phase at any temperature and composition in the phase diagram. Since no experimental data can be obtained for these kind of unstable phases (the Am-U phase diagram never exhibits a phase with the $\beta$-Pu crystal structure), the ${ }^{0} L$ parameters take generally a high positive value to induce a strong increase (destabilization) of the Gibbs energy. In the present assessment, the $L_{A m, U}^{\beta-P u}, L_{A m, U}^{\gamma-P u}$ and $L_{A m, U}^{\delta^{\prime}-P u}$ parameters have been chosen equal to $L_{A m, U}^{\text {Liquid }}\left({ }^{0} L=+40000 \mathrm{~J} / \mathrm{mol}\right)$. Note that the values selected by Kurata are included between +5000 and $+50000 \mathrm{~J} / \mathrm{mol}$ (Table 3).

Based on the previous and present CALPHAD assessments (Tables 2-3), isothermal sections of the Pu-U-Am system are presented in Fig. 7 (Kurata's version [8, 9]), Fig. 8 (present study) and Fig. 9 (present study with less stable bcc phase in the Am-Pu binary represented by Eq. 20). For this last case, only the isotherms that differ from the ones presented in Fig. 8 are plotted. As observed on all predictions, the liquid miscibility gap extends from the Am-U side to the interior of the Am-Pu-U isotherm (see 
at $\left.1227^{\circ} \mathrm{C} / 1500 \mathrm{~K}\right)$, hence indicating an improvement of the poor miscibility of Am and $\mathrm{U}$ in the liquid phase by adding $\mathrm{Pu}$. This result is in agreement with the results of Ogawa [2]. By decreasing the temperature to $927^{\circ} \mathrm{C}(1200 \mathrm{~K})$, the poor solubility of Am and $\mathrm{U}$ is, once again, highlighted by the formation of a large bcc $(\gamma-U)+$ fcc $(\beta$-Am) domain. A slight difference between the three assessments comes from the appearance of a Liquid $+\mathrm{fcc}(\beta-\mathrm{Am}, \delta-\mathrm{Pu})+\operatorname{bcc}(\gamma-\mathrm{Am}, \epsilon-\mathrm{Pu})$ domain on the Am-Pu side in Fig. 8 (final assessment). This is due to the stability of the bcc phase ( $\gamma$-Am, $\epsilon$ $\mathrm{Pu}$ ) calculated at high temperature for the Am-Pu system (Fig. 4a). These CALPHAD predictions are quite different from the one made by Ogawa (Fig. 1d, [2]). Indeed, in Ogawa's case, a phase separation between the fcc and bcc phase is also observed with tie-lines running parallel to the Am-U side, but a stable fcc domain and a large bcc domain are also predicted. The strong stability of the bcc phase comes from the three underlying systems. In fact, the bcc phase is stable over the whole composition range for the $\mathrm{Am}-\mathrm{Pu}$ and the $\mathrm{Pu}-\mathrm{U}$ systems (Fig. 1b-c), moreover both the $\gamma-\mathrm{Am}$ (bcc) and $\gamma-\mathrm{U}$ allow a partial solubility of $\mathrm{U}$ and Am, respectively (Fig. 1a). On the contrary, previous (Fig. 2a) and present (Fig. 6) CALPHAD assessments exhibit a poor solubility of both Am and $\mathrm{U}$ in the bcc phase. Then, by cooling the system temperature down to $627^{\circ} \mathrm{C}(900 \mathrm{~K})$, all predicted isothermal sections exhibit a mixture of phases from the Am-Pu and Pu-U binary systems (Fig. 7-9). This indicates, in addition to the fact that all tie-lines are parallel to the Am-U side, the very poor miscibility of Am and $U$ in any phase of the system. In addition, a small liquid region is still present at the Pu-rich corner, and corresponds to the low minimum-melting temperature calculated for the $\mathrm{Pu}-\mathrm{U}$ binary by Kurata $\left(619^{\circ} \mathrm{C},[8]\right)$ and Perron et al. $\left(608^{\circ} \mathrm{C},[19]\right)$. By decreasing the temperature down to $327^{\circ} \mathrm{C}(600 \mathrm{~K})$, the present CALPHAD assessment (Fig. 8) differs quite largely from the previous one (Fig. 7) because of the differences between the $\mathrm{Am}-\mathrm{Pu}$ binary assessments. Indeed, the fcc $+\alpha$-Am and the fcc phase domains stable at $327^{\circ} \mathrm{C}$ in the Kurata's version (Fig. 2b, [9]) extend the precipitation of the fcc phase in all domains of the $\mathrm{Pu}-\mathrm{U}-\mathrm{Am}$ ternary. On the contrary, the ab initio informed $\mathrm{Am}-\mathrm{Pu}$ phase diagram develops a small but larger stability domain for the $\alpha$-Am solid solution (Fig. 4a). This difference prompts the precipitation of a large $\alpha-\mathrm{Am}+\alpha-\mathrm{U}+\zeta$ domain in the Pu-U-Am system and, as a result, reduces the presence of the fcc phase to around 
half of the regions of the isothermal section. Finally, the fcc phase is still present in many domains of the Kurata's version at room temperature because of the Am-Pu binary, which exhibits a fcc solid solution at room temperature (Fig. 2b). However, the ab initio informed Am-Pu assessment used in the present study displays a low-lying eutectoid decomposition ( $\mathrm{fcc} \rightarrow \alpha$-Am $+\alpha$-Pu), which is in better agreement with the third law of thermodynamics (its application precludes the existence of an fcc solid solution down to $0 \mathrm{~K}$ ) [20]. The resulting isothermal section around room temperature (Fig. 8) exhibits no fcc phase at thermodynamic equilibrium.

\section{Discussion}

The ab initio informed thermodynamic re-assessment of the Am-U system (Fig. 6) was successfully performed and compared with previous assessments [2,9]. The most interesting feature is the poor solubility of Am and $\mathrm{U}$ in all solid solutions ( $\mathrm{fcc}$ and bcc). This result is directly related to the highly positive heats of formation calculated in both the fcc and bcc phases (Fig. 5a) that induce a tendency towards phase separation. For instance, the U-Am metastable fcc and bcc phases plotted in Fig. 5b exhibit large miscibility gaps. The top of these non-symmetrical miscibility gaps are located at around 30 at.\% U and revealed - relatively speaking - a greater solubility of Am in $\mathrm{U}$ phases than vice versa. As a consequence, the $\gamma-\mathrm{U}$ phase (bcc) is the only one presenting a phase stability region in Fig. 6.

Overall, this predicted poor miscibility is in agreement with the results of Kurata (Fig. 2a) but is slightly different from the one calculated by Ogawa (Fig. 1a). However, the present assessment is built on a reliable energetic basis with consistent interaction parameters (the chemical trend is not structure dependent between fcc and bcc, Table 3), and thus can be considered more trustworthy. Based on this new assessment (Fig. 6), it would be interesting to conduct new experiments on a $\mathrm{U}-\mathrm{x}$ at. \% $\mathrm{Am}(\mathrm{x}=2$ 10) alloy to confirm the solubility limit of Am in the $\gamma-\mathrm{U}$ (bcc) phase. Indeed, the maximum solubility of Am in $\gamma$-U predicted in the present study is around 1.6 at.\% and is quite far from the 10 at.\% calculated by Ogawa [2]. It is worth noting that temperature-dependent contribution to the RK interactions (Eq. 12) for the fcc and bcc 
phases have not been assessed (Table 3). However, with new experimental data on $\mathrm{U}-\mathrm{x}$ at.\% Am alloys, the present CALPHAD thermodynamic database can be refine by optimizing these temperature-dependent parameters. As a perfect example, both the fcc and bcc phases of the Am-Pu system exhibit positive heats of formation at $0 \mathrm{~K}$ (Fig. 5a), leading to the formation of metastable miscibility gaps (Fig. 5b). Please note that the miscibility gaps plotted in Fig. 5b are calculated using Eq. 7 but considering only the T-independent RK interaction parameters of Eq. 12 (composition dependence of the excess enthalpy). This tendency to phase separation is less pronounced compared with the one of the Am-U system but is present. However, the assessment performed by Turchi et al. [20], based on ab initio data for the temperature-independent interactions and on experimental measurements at high-temperature for the temperature-dependent interactions, revealed quite large temperature-dependent parameters (Table 3 ) for both fcc and bcc phases that reflect their stabilization by entropy effect. Thus, these proposed experiments would help to confirm and refine the present $a b$ initio informed thermodynamic assessment.

As observed in Fig. 5, the ab initio energetics (heats of formation) and the resulting metastable miscibility gaps for the fcc and bcc phases of the U-Am and Pu-Am systems follow the same trend. In both cases, the tendency towards phase separation is highlighted with an emphasis on the bcc phase. In order to complete the series of X-Am alloys with $\mathrm{X}=\mathrm{U}, \mathrm{Np}, \mathrm{Pu}$ (following the actinide series by adding one electron per step), the heats of formation of the Np-Am bcc phase have been calculated at $\mathrm{T}=0 \mathrm{~K}$ (FR-EMTO-CPA) and are presented in Fig. 5a. As for the U-Am and Pu-Am systems, the calculated bcc heats of formation are positive. Due to the more symmetrical values of the Np-Am heats of formation, the resulting bcc miscibility gap is between the ones predicted for the U-Am and Pu-Am systems (Fig. 5b). Thus, these ab initio calculations performed for the Np-Am system validate the general trend regarding the phase stability of the $\mathrm{X}$-Am systems $(\mathrm{X}=\mathrm{U}, \mathrm{Np}, \mathrm{Pu})$.

The thermodynamic data of the ab initio informed Pu-U [19] and Am-Pu [20] binaries have been combined with consistency with the Am-U binary to study the ternary $\mathrm{Pu}-\mathrm{U}-\mathrm{Am}$ system. Let us recall that no experimental data are available for this ternary system. As a consequence, the solubility of Am in Pu-U intermediate phases ( $\eta$ and 
$\zeta)$ is neglected. Moreover, contribution to the excess Gibbs energy from ternary interaction parameters is not considered. For instance, the interactions in the bcc phase where the 3 elements are present - are based on the interactions from the binaries without any ternary correction. Ultimately, other compounds that only form in the ternary system may exist and can not be introduced in the present study without new experimental data. This implies that the Pu-U-Am predictions presented should be considered as representations of systems if not in the stable equilibrium, at least in the metastable one [43]. Should more experimental data on solubilities and new compounds in the ternary system be available, it would be possible to introduce their thermodynamic description in the database. Meanwhile, we selected various alloy compositions to study the impact of Am on the Pu-U phase stability. The first alloy is a Pu-rich alloy (Pu- 5 at.\% U) whereas the second one is a U-rich alloy (Pu- 78 at.\% U). Please note that the Pu-rich alloy composition has been selected to study the impact of daughter products on Pu-based systems and that the U-rich one has been chosen with regards to metallic fuels (Pu-70U-10Zr in wt.\% [44]). For these two alloys, the impact of an Am content increase (between 0 and 10 at.\% with a simultaneous decrease of the $\mathrm{Pu}$ content) on the phase stability has been calculated and is presented in Fig. 10. As observed in Fig. 10a, the increase of Am at low temperature induces the precipitation of $\alpha$-Am (as the $\zeta$ phase admits no Am solubility and the solubility of Am in $\alpha$-Pu is very poor). However, by heating up the system, a clear stabilization of the fcc phase is noted. This behavior, symbolized by three alloy compositions $\left(\mathrm{Pu}_{.95} \mathrm{U}_{.05}\right.$, $\mathrm{Pu}_{.90} \mathrm{U}_{.05} \mathrm{Am}_{.05}, \mathrm{Pu}_{.85} \mathrm{U}_{.05} \mathrm{Am}_{.10}$ ), is highlighted by property diagrams in Fig. 11a-c. Am acts as a strong stabilizer of the fcc phase, and simultaneously destabilizes the bcc and the complex $\eta$ phases. Following the same procedure, Am seems to promote the fcc phase stability in Fig. 10b. Thus, three alloy compositions are reported in Fig. 11d-f $\left(\mathrm{Pu}_{.22} \mathrm{U}_{.78}, \mathrm{Pu}_{.17} \mathrm{U}_{.78} \mathrm{Am}_{.05}, \mathrm{Pu}_{.12} \mathrm{U}_{.78} \mathrm{Am}_{.10}\right)$. For this system, an Am increase will induce a miscibility gap at high temperature in both the liquid and bcc phases. At inter395 mediate temperature, a slight increase of the fcc-phase stability is revealed. Finally, the Am increase promotes the $\alpha$-Am phase at low temperature and the accompanying $\mathrm{Pu}$ decrease induces an increase of the $\alpha$-U phase fraction and a decrease of the $\zeta$-phase fraction. Thus, the impact of Am on the U-rich alloy at intermediate temperature is less 
pronounced compared with the one on the Pu-rich alloy but could be more problematic. Indeed, the impact of alloying and thermal treatment on Pu-rich alloys is generally considered as a function of the fcc-phase stability ( $\delta$-Pu phase) $[19,45,46]$. As Am tends to stabilize the fcc phase, its impact can be considered as beneficial. However, since metallic fuels are mostly ductile bcc alloys, the appearance of a fcc phase due to an Am increase at working temperature can lead to undesirable physical properties of the fuel (stress, changes in thermal conductivity...). Therefore the Am impact on stability and physical properties of U-rich alloys cannot be ignored or underestimated.

Ultimately, the predicted isotherms can also be used to refine the binary assessments. Indeed, as the experiments on actinide alloys are challenging, the opportunity to infer results on underlying binaries from existing ternary samples is highly valuable. For instance, the small bcc domain observed in Fig. 8 at $927^{\circ} \mathrm{C}$ at the U-rich corner originates mainly from the Pu-U system (Fig. 3) but is restricted by the poor solubility of $\mathrm{Am}$ in $\gamma$-U (bcc, Fig. 6). A Pu. ${ }_{.10} \mathrm{U}_{.86 \pm .02} \mathrm{Am}_{.04 \pm .02}$ sample (see symbols in Fig. 8) would help to define the bcc solubility limit in the ternary system and retrospectively to refine the solubility limit of $\mathrm{Am}$ in $\gamma$-U (as this last has been evaluated without experimental data). Moreover, by decreasing the temperature of the system below $327^{\circ} \mathrm{C}$ (Fig. 8), the solubility of Am into the complex $\zeta$ phase or the $\alpha$-U phase can be studied. Based on the same sample and if thermodynamic equilibrium can be reach, the results obtained at low temperature would allow to solve some differences observed between the assessment of Kurata (Fig. 7) and the present assessment (Fig. 8).

\section{Conclusion}

An ab initio informed thermodynamic assessment of the Pu-U-Am system has been performed by recasting the fcc and/or bcc phase ab initio energetics of the three binaries (Am-U, Pu-U and Am-Pu) in the CALPHAD framework. A very poor miscibility between $\mathrm{Am}$ and $\mathrm{U}$ has been predicted with a high-temperature liquid miscibility gap. Regarding the phase stability of the ternary system, Am acts as a strong fcc-phase stabilizer for the Pu-rich alloys whereas this effect is less pronounced for the U-rich alloys. As experiments on actinide materials are costly, time consuming and require 
special training, the use of the present thermodynamic database can help to guide new experiments to fully grasp the understanding of the Pu-U-Am ternary system. For instance, selected compositions can help to characterize the solubility of Am in $\gamma-\mathrm{U}$ (bcc) and the solubility of $\mathrm{Am}$ in the intermediate $\zeta$ phase (from the Pu-U system). Finally, new data can be used to refine the present thermodynamic database.

\section{Acknowledgments}

This work was performed under the auspices of the U.S Department of Energy ${ }_{435}$ by Lawrence Livermore National Laboratory under contract DE-AC52-07NA27344. Work at LLNL was funded by the Laboratory Directed Research and Development Program under project tracking code 12-SI-008. This work was done as part of the international agreement on cooperation between DOE-NNSA and CEA-DAM in fundamental science supporting stockpile stewardship. A.P. gratefully acknowledges the financial support from the CEA-Centre de Valduc (France), and the Post-doctoral program at LLNL.

\section{References}

[1] U.S. DOE Nuclear Energy Research Advisory Committee and the Generation IV International Forum, A Technology Roadmap for Generation IV Nuclear Energy Systems, Tech. Rep. GIF-002-00, US Department of Energy Report (December 2002).

[2] T. Ogawa, Alloying behavior among U, Np, Pu and Am predicted with the Brewer valence bond model, JOURNAL OF ALLOYS AND COMPOUNDS 194 (1) (1993) 1-7. doi : $\{10.1016 / 0925-8388$ (93) 90636-2\}.

[3] L. Bewer, R. H. Lamoreaux, Thermochemical properties, ATOMIC ENERGY REVIEW (7) (1980) 11-191.

[4] T. Inoue, T. Matsumura, A. Sasahara, L. Koch, J. C. Spirlet, Transmutation of transuranium elements by a metallic fuel FBR, in: Information Exchange Meeting 
on Actinide and Fission Product Separation and Transmutation, OECD Nuclear Energy Agency, Paris, 1990, pp. 397-423.

[5] L. Kaufman, H. Bernstein, Computer Calculation of Phase Diagrams with Special Reference to Refractory Metals, Refractory Materials, Academic Press, 1970.

[6] N. Saunders, A. Miodownik, CALPHAD (Calculation of Phase Diagrams): A Comprehensive Guide, Pergamon Materials Series, Elsevier Science, 1998.

[7] H. Lukas, S. Fries, B. Sundman, Computational thermodynamics: the CALPHAD method, Cambridge University Press, 2007.

[8] M. Kurata, Thermodynamic database on U-Pu-Zr-Np-Am-Fe alloy system I - Reevaluation of U-Pu-Zr alloy system, in: Rao, L and Tobin, JG and Shuh, DK (Ed.), ACTINIDES 2009, Vol. 9 of IOP Conference Series-Materials Science and Engineering, IOP PUBLISHING LTD, DIRAC HOUSE, TEMPLE BACK, BRISTOL BS1 6BE, ENGLAND, 2010, Actinides Conference, San Francisco, CA, JUL 12-17, 2009. doi : $\{10.1088 / 1757-899 x / 9 / 1 / 012022\}$.

[9] M. Kurata, Thermodynamic database on U-Pu-Zr-Np-Am-Fe alloy system II Evaluation of $\mathrm{Np}, \mathrm{Am}$, and Fe containing systems-, in: Rao, L and Tobin, JG and Shuh, DK (Ed.), ACTINIDES 2009, Vol. 9 of IOP Conference SeriesMaterials Science and Engineering, IOP PUBLISHING LTD, DIRAC HOUSE, TEMPLE BACK, BRISTOL BS1 6BE, ENGLAND, 2010, Actinides Conference, San Francisco, CA, JUL 12-17, 2009. doi : \{10 .1088/1757-899X/9/1/ $012023\}$.

[10] B. Sundman, B. Jansson, J.-O. Andersson, The Thermo-Calc databank system, CALPHAD-COMPUTER COUPLING OF PHASE DIAGRAMS AND THERMOCHEMISTRY 9 (2) (1985) 153-190. doi:\{10.1016/ $0364-5916$ (85) 90021-5\}.

[11] J. O. Andersson, T. Helander, L. H. Höglund, P. F. Shi, B. Sundman, Thermo-Calc \& DICTRA, computational tools for materials science, CALPHAD-COMPUTER 
COUPLING OF PHASE DIAGRAMS AND THERMOCHEMISTRY 26 (2) (2002) 273-312. doi : $\{10.1016 / \mathrm{S} 0364-5916$ (02) 00037-8\}.

[12] M. Kurata, Materials Models and Simulations for Nuclear Fuels (MMSNF-6), CD-ROM, Tokyo University, 1997.

${ }_{485}$ [13] F. H. Ellinger, K. A. Johnson, V. O. Struebin, Plutonium-Americium system, JOURNAL OF NUCLEAR MATERIALS 20 (1) (1966) 83-86. doi : $\{10$. $1016 / 0022-3115$ (66) 90024-9\}.

[14] F. Ellinger, R. Elliott, E. Cramer, The Plutonium - Uranium System, JOURNAL OF NUCLEAR MATERIALS 1 (3) (1959) 233-243. doi : \{10.1016/ 0022-3115(59) 90019-4\}.

[15] D. Calais, M. Dupuy, M. Mouchino, A. Y. Portnoff, A. Van Craeynest, Diffusion of plutonium in the solid state, in: A. Kay, M. Waldron (Eds.), Plutonium 1965, Chapman and Hall, London, 1967, pp. 358-391.

[16] Y. Okamoto, A. Maeda, Y. Suzuki, T. Ohmichi, Investigation of the Pu-U phasediagram, JOURNAL OF ALLOYS AND COMPOUNDS 213 (1994) 372-374, International Conference on Actinides, SANTE FE, NM, SEP 19-24, 1993. doi: $\{10.1016 / 0925-8388$ (94) 90935-0\}.

[17] AEC Research and development report, Tech. rep., Mound Laboratory Report MLM-1445 (1967).

${ }_{500}$ [18] K. Nakajima, T. Iwai, A. Yasuo, M. Kurata, K. Nakamura, Y. Arita, Private communication.

[19] A. Perron, P. E. A. Turchi, A. Landa, P. Söderlind, B. Ravat, B. Oudot, M. Kurata, Thermodynamic re-assassment of the Pu-U system and its application to the ternary Pu-U-Ga System, JOURNAL OF NUCLEAR MATERIALS 454 (2014) $505 \quad 81-95$.

[20] P. E. A. Turchi, A. I. Landa, P. A. Söderlind, Thermodynamic assessment of the Am-Pu system with input from ab initio, JOURNAL OF NUCLEAR MATE- 
RIALS 418 (1-3) (2011) 165-173. doi : $\{10.1016 / j$. jnucmat. 2011. $06.034\}$.

[21] A. Dinsdale, SGTE data for pure elements, CALPHAD-COMPUTER COUPLING OF PHASE DIAGRAMS AND THERMOCHEMISTRY 15 (4) (1991) 317-425. doi : $\{10.1016 / 0364-5916$ (91) 90030-N\}.

[22] P. E. A. Turchi, L. Kaufman, S. Zhou, Z.-K. Liu, Thermostatics and kinetics of transformations in Pu-based alloys, JOURNAL OF ALLOYS AND COMPOUNDS 444 (2007) 28-35, 4th Topical Conference on Plutonium and Actinides/Plutonium Futures - The Science 2006, Pacific Grove, CA, JUL 09-13, 2006. doi: $\{10.1016 / j . j a l l c o m .2006 .10 .046\}$.

[23] U. Kattner, The thermodynamic modeling of multicomponent phase equilibria, JOM-JOURNAL OF THE MINERALS METALS \& MATERIALS SOCIETY 49 (12) (1997) 14-19. doi : \{10.1007/s11837-997-0024-5\}.

[24] O. Redlich, A. Kister, Algebraic representation of thermodynamic properties and the classification of solutions, INDUSTRIAL AND ENGINEERING CHEMISTRY 40 (2) (1948) 345-348. doi : $\{10.1021$ / ie50458a036\}.

[25] Y. Muggianu, M. Gambino, J. Bros, Enthalpies of formation of liquid alloys bismuth-gallium-tin at $723 \mathrm{~K}$ - Choice of an analytical representation of integral and partial thermodynamic functions of mixing for this ternary-system, JOURNAL DE CHIMIE PHYSIQUE ET DE PHYSICO-CHIMIE BIOLOGIQUE 72 (1) (1975) 83-88.

[26] S. Bajaj, A. Landa, P. Söderlind, P. E. A. Turchi, R. Arroyave, The U-Ti system: Strengths and weaknesses of the CALPHAD method, JOURNAL OF NUCLEAR MATERIALS 419 (1-3) (2011) 177-185. doi : \{10.1016/j.jnucmat. $2011.08 .050\}$.

[27] P. Söderlind, P. E. A. Turchi, A. Landa, V. Lordi, Ground-state properties of rare-earth metals: an evaluation of density-functional theory, JOURNAL OF 
PHYSICS: CONDENSED MATTER 26 (41) (2014) 416001-1-8. doi : $\{10$. $1088 / 0953-8984 / 26 / 41 / 416001\}$.

[28] S. Dudarev, G. Botton, S. Savrasov, Z. Szotek, W. Temmerman, A. Sutton, Electronic structure and elastic properties of strongly correlated metal oxides from first principles: LSDA+U, SIC-LSDA and EELS study of UO2 and NiO, PHYSICA STATUS SOLIDI AAPPLICATIONS AND MATERIALS SCIENCE 166 (1) (1998) 429443. http://dx.doi.org/10.1002/(SICI)1521-396X(199803)166:1<429::AIDPSSA429>3.0.CO;2-F doi : $\{10$.1002 / (SICI) 1521-396X (199803) $166: 1<429::$ AID-PSSA $429>3.0 . \mathrm{CO} ; 2-\mathrm{F}\}$.

[29] P. Söderlind, G. Kotliar, K. Haule, P. M. Oppeneer, D. Guillaumont, Computational modeling of actinide materials and complexes, MRS BULLETIN 35 (11) (2010) 883-888. doi : $\{10.1557 / \mathrm{mrs} 2010.715\}$.

[30] P. Söderlind, B. Sadigh, Density-functional calculations of alpha, beta, gamma, delta, delta', and epsilon plutonium, PHYSICAL REVIEW LETTERS 92 (18) (2004) 185702-1-4. doi: $\{10.1103 /$ PhysRevLett. 92.185702$\}$.

[31] P. Söderlind, K. T. Moore, A. Landa, B. Sadigh, J. A. Bradley, Pressure-induced changes in the electronic structure of americium metal, PHYSICAL REVIEW B 84 (7) (2011) 075138-1-8. doi : \{10 .1103/PhysRevB. 84 . 075138\}.

[32] A. Landa, P. Söderlind, P. E. A. Turchi, L. Vitos, A. Ruban, Density-functional study of Zr-based actinide alloys: 2. U-Pu-Zr system, JOURNAL OF NUCLEAR MATERIALS 393 (1) (2009) 141-145. doi: $\{10.1016 / j \cdot j$ nucmat. $2009.05 .014\}$.

[33] A. Landa, P. Söderlind, P. E. A. Turchi, L. Vitos, O. E. Peil, A. V. Ruban, Densityfunctional study of bec $\mathrm{Pu}-\mathrm{U}, \mathrm{Pu}-\mathrm{Np}, \mathrm{Pu}-\mathrm{Am}$, and $\mathrm{Pu}-\mathrm{Cm}$ alloys, JOURNAL OF NUCLEAR MATERIALS 408 (1) (2011) 61-66. doi : \{10.1016/j . jnucmat.2010.10.066\}. 
[34] P. E. A. Turchi, P. Söderlind, A. I. Landa, From Electronic Structure to Thermodynamics of Actinide-Based Alloys, JOM 66 (3) (2014) 375-388. doi : $\{10.1007 / \mathrm{s} 11837-014-0882-6\}$.

${ }_{565}$ [35] A. Landa, P. Söderlind, P. E. A. Turchi, Density-functional study of U-Mo and U-Zr alloys, JOURNAL OF NUCLEAR MATERIALS 414 (2) (2011) 132-137. doi: $\{10.1016 / j . j n u c m a t .2011 .02 .019\}$.

[36] H. Okamoto, Am-U (americium-uranium), JOURNAL OF PHASE EQUILIBRIA 20 (4) (1999) 452. doi : \{10.1361/105497199770335631\}.

570 [37] H. Okamoto, Am-U (Americium-Uranium), JOURNAL OF PHASE EQUILIBRIA AND DIFFUSION 33 (6) (2012) 503. doi:\{10.1007/ s11669-012-0121-1\}.

[38] H. Okamoto, Am-Pu (americium-plutonium), JOURNAL OF PHASE EQUILIBRIA 20 (4) (1999) 451. doi : \{10.1361/105497199770335622\}.

[39] H. Okamoto, Pu-U (plutonium-uranium), JOURNAL OF PHASE EQUILIBRIA 17 (4) (1996) 372.

[40] M. Kurata, Thermodynamic assessment of the $\mathrm{Pu}-\mathrm{U}, \mathrm{Pu}-\mathrm{Zr}$, and $\mathrm{Pu}-\mathrm{U}-\mathrm{Zr}$ systems, CALPHAD-COMPUTER COUPLING OF PHASE DIAGRAMS AND THERMOCHEMISTRY 23 (3-4) (1999) 305-337, XXVII CALPHAD Meeting, BEIJING, PEOPLES R CHINA, MAY, 1998. doi:\{10.1016/ S0364-5916(00)00004-3\}.

[41] V. D. Shushakov, N. S. Kosulin, N. T. Chebotarev, The Phase Diagram of Plutonium-Americium Alloys, in: Questions of Atomic Science and Technology, SERIES MATERIAL SCIENCE AND NEW MATERIALS (3) (1990) 14-15.

${ }_{585}$ [42] P. Gotcu-Freis, J. Y. Colle, C. Gueneau, N. Dupin, B. Sundman, R. J. M. Konings, A thermodynamic study of the Pu-Am-O system, JOURNAL OF NUCLEAR MATERIALS 414 (3) (2011) 408-421. doi: \{10.1016/j.jnucmat. $2011.05 .014\}$. 
[43] P. E. A. Turchi, A. I. Landa, Thermodynamic assessment of Al-Mo-Si-U, Tech. Rep. LLNL-TR-603054, Lawrence Livermore National Laboratory (2012).

[44] Y. S. Kim, G. L. Hofman, A. M. Yacout, Migration of minor actinides and lanthanides in fast reactor metallic fuel, JOURNAL OF NUCLEAR MATERIALS 392 (2) (2009) 164-170, 2nd Symposium on Nuclear Fuels and Structural Materials for Next Generation Nuclear Reactors, Anaheim, CA, JUN 10-12, 2008.

${ }_{595}$ doi: $\{10.1016 / j . j n u c m a t .2009 .03 .043\}$.

[45] B. Ravat, B. Oudot, A. Perron, F. Lalire, F. Delaunay, Phase transformations in PuGa 1 at.\% alloy: Study of whole reversion process following martensitic transformation, JOURNAL OF ALLOYS AND COMPOUNDS 580 (2013) 298-309. doi: $\{10.1016 / j \cdot j a 11$ com.2013.04.142\}.

[46] A. Perron, B. Ravat, B. Oudot, F. Lalire, K. Mouturat, F. Delaunay, Phase transformations in Pu-Ga alloy: Synergy between simulations and experiments to elucidate direct and indirect reversion competition, ACTA MATERIALIA 61 (19) (2013) 7109-7120. doi : $\{10.1016 / j$.actamat. 2013.07 .060$\}$. 
Tables

${ }_{605}$ Table 1. Am, Pu and U crystal structures data, taken from [36, 37, 38, 39].

\begin{tabular}{|c|c|c|c|c|c|}
\hline Phase & $\begin{array}{l}\text { CALPHAD } \\
\text { Designation }\end{array}$ & Pearson symbol & Space group & $\begin{array}{c}\text { Struckturbericht } \\
\text { Designation }\end{array}$ & Prototype \\
\hline \multicolumn{6}{|c|}{ Pure phases } \\
\hline$\alpha-\mathrm{Am}$ & DHCP & $h P 4$ & $P 6_{3} / m m c$ & $A 3^{\prime}$ & $\alpha$-La \\
\hline$\beta-A m$ & FCC_A1 & $c F 4$ & $F m \overline{3} m$ & $A 1$ & $\mathrm{Cu}$ \\
\hline$\gamma-\mathrm{Am}$ & BCC_A2 & $c I 2$ & $\operatorname{Im} \overline{3} m$ & $A 2$ & $\mathrm{~W}$ \\
\hline$\alpha-\mathrm{U}$ & Orthorhombic_A20 & $o C 4$ & $\mathrm{Cmcm}$ & $A 20$ & $\alpha-\mathrm{U}$ \\
\hline$\beta-\mathrm{U}$ & Tetragonal_U & $t P 30$ & $P 4_{2} / m n m$ & $A_{b}$ & $\beta-\mathrm{U}$ \\
\hline$\gamma-\mathrm{U}$ & BCC_A2 & $c I 2$ & $\operatorname{Im} \overline{3} m$ & $A 2$ & $\mathrm{~W}$ \\
\hline$\alpha-\mathrm{Pu}$ & Alpha_Pu & $m P 16$ & $P 2_{1} / m$ & - & $\alpha-\mathrm{Pu}$ \\
\hline$\beta-\mathrm{Pu}$ & Beta_Pu & $m C 34$ & $C 2 / m$ & - & $\beta-\mathrm{Pu}$ \\
\hline$\gamma-\mathrm{Pu}$ & Gamma_Pu & $o F 8$ & $F d d d$ & - & $\gamma-\mathrm{Pu}$ \\
\hline$\delta-\mathrm{Pu}$ & FCC_A1 & $c F 4$ & $F m \overline{3} m$ & $A 1$ & $\mathrm{Cu}$ \\
\hline$\delta^{\prime}-\mathrm{Pu}$ & Tetragonal_A6 & $t I 2$ & $I 4 / \mathrm{mmm}$ & $A 6$ & In \\
\hline$\epsilon-\mathrm{Pu}$ & BCC_A2 & $c I 2$ & $\operatorname{Im} \overline{3} m$ & $A 2$ & $\mathrm{~W}$ \\
\hline \multicolumn{6}{|c|}{ Intermediate phases of the $\mathrm{Pu}-\mathrm{U}$ system } \\
\hline$\zeta$ & Zeta & $c P 58$ & - & - & - \\
\hline$\eta$ & Eta & $t P 52$ & - & - & - \\
\hline
\end{tabular}


Table 2. Gibbs energies (lattice stabilities) in $\mathrm{J} / \mathrm{mol}$ for the pure elements Am, $\mathrm{U}$ and $\mathrm{Pu}$.

\begin{tabular}{|c|c|c|}
\hline Gibbs energy & Kurata $[8,9]$ & Present study \\
\hline \multicolumn{3}{|c|}{ Pure phases } \\
\hline${ }^{0} G_{A m}^{\alpha-P u},{ }^{0} G_{A m}^{\alpha-U},{ }_{A m}^{\beta}, G_{A m}^{\beta-U},{ }^{0} G_{A m}^{\gamma-P u},{ }^{0} G_{A m}^{\delta^{\prime}-P u}$ & $+5000+{ }^{0} G_{A m}^{\alpha-A m}$ & $+5000+{ }^{0} G_{A m}^{\alpha-A m}$ \\
${ }^{0} G_{U}^{\alpha-A m}$ & $+5000+{ }^{0} G_{U}^{\gamma-U}$ & $+5000+{ }^{0} G_{A m}^{\alpha-A m}[9]$ \\
${ }^{0} G_{U}^{\beta-A m},{ }^{0} G_{U}^{\delta-P u},{ }^{0} G_{U}^{\delta^{\prime}-P u}$ & $+5000+{ }^{0} G_{U}^{\gamma-U}$ & $+2000+{ }^{0} G_{U}^{\alpha-U}[40]$ \\
${ }^{0} G_{U}^{\alpha-P u}$ & $+5000+{ }^{0} G_{U}^{\alpha-U}$ & - \\
${ }^{0} G_{U}^{\beta-P u}, G_{U}^{\gamma-P u}$ & $+5000+{ }^{0} G_{U}^{\alpha-U}$ & $+2000+{ }^{0} G_{U}^{\alpha-U}[40]$ \\
${ }^{0} G_{P u}^{\alpha-A m}$ & $+5000+{ }^{0} G_{P u}^{\delta-P u}$ & $+1680+{ }^{0} G_{P u}^{\delta-P u}[20]$ \\
${ }^{0} G_{P u}^{\alpha-U}$ & $+652.7+{ }^{0} G_{P u}^{\beta-P u}$ & $+2026+{ }^{0} G_{P u}^{\alpha-P u}[40]$ \\
${ }^{0} G_{P u}^{\beta-U}$ & $+209.6+{ }^{0} G_{P u}^{\delta^{\prime}-P u}$ & $+227.5+{ }^{0} G_{P u}^{\delta-P u}[40]$ \\
\hline \multicolumn{2}{|c|}{ Intermediate phases of the Pu-U system } \\
\hline${ }^{0} G_{A m}^{\zeta}$ & $+5000+{ }^{0} G_{A m}^{\alpha-A m}$ & - \\
${ }^{0} G_{A m}^{\eta}$ & $+5000+{ }^{0} G_{A m}^{\alpha-A m}$ & - \\
${ }^{0} G_{U}^{\zeta}$ & $+337.8+{ }^{0} G_{U}^{\alpha-U}$ & $+332.1+{ }^{0} G_{U}^{\gamma-U}[40]$ \\
${ }^{0} G_{U}^{\eta}$ & $+118.7+{ }^{0} G_{U}^{\beta-U}$ & $+229.2+{ }^{0} G_{U}^{\beta-U}[40]$ \\
${ }^{0} G_{P u}^{\zeta}$ & $+500+{ }^{0} G_{P u}^{\beta-P u}$ & $+500+{ }^{0} G_{P u}^{\epsilon-P u}[40]$ \\
${ }^{0} G_{P u}^{\eta}$ & $+51.1+{ }^{0} G_{P u}^{\gamma-P u}$ & $+103.4+{ }^{0} G_{P u}^{\delta-P u}[40]$ \\
\hline
\end{tabular}


Table 3. Interaction parameters (in $\mathrm{J} / \mathrm{mol}$ or $\mathrm{J} / \mathrm{mol} / \mathrm{K}$ ) for solution phases of the $\mathrm{Am}-\mathrm{U}, \mathrm{Am}-\mathrm{Pu}$ and $\mathrm{Pu}-\mathrm{U}$ systems. 


\begin{tabular}{|c|c|c|c|c|c|}
\hline Phase & System & $\begin{array}{c}\text { RK } \\
\text { Parameters }\end{array}$ & Ogawa [2] & Kurata $[8,9]$ & $\begin{array}{l}\text { Present study } \\
\text { plus }[19,20]\end{array}$ \\
\hline Liquid & $\begin{array}{l}\mathrm{Am}-\mathrm{U} \\
\mathrm{Am}-\mathrm{Pu} \\
\mathrm{Pu}-\mathrm{U}\end{array}$ & $\begin{array}{l}{ }^{0} L \\
{ }^{1} L \\
{ }^{0} L \\
{ }^{1} L \\
{ }^{0} L \\
{ }^{1} L\end{array}$ & $\begin{array}{c}+23982 \\
-3507 \\
+1177 \\
-141.5 \\
0 \\
0\end{array}$ & $\begin{array}{c}+50000 \\
- \\
+5495.9-1.7762 \mathrm{~T} \\
- \\
+32231-31.465 \mathrm{~T} \\
-8980.2\end{array}$ & $\begin{array}{c}+40000 \\
- \\
+39560-55.856 \mathrm{~T} \\
+3281.4-4.924 \mathrm{~T} \\
+13839-19.6 \mathrm{~T} \\
-7093\end{array}$ \\
\hline $\begin{array}{c}\text { bcc } \\
(\gamma-\mathrm{Am}, \gamma-\mathrm{U}, \epsilon-\mathrm{Pu})\end{array}$ & $\begin{array}{l}\mathrm{Am}-\mathrm{U} \\
\mathrm{Am}-\mathrm{Pu} \\
\mathrm{Pu}-\mathrm{U}\end{array}$ & $\begin{array}{l}{ }^{0} L \\
{ }^{1} L \\
{ }^{0} L \\
{ }^{1} L \\
{ }^{0} L \\
{ }^{1} L\end{array}$ & $\begin{array}{l}+27055 \\
-4457 \\
+1026 \\
-127.1 \\
+3600 \\
+1300\end{array}$ & $\begin{array}{c}+50000 \\
- \\
+7528.57 \\
+2.7353 \\
+19374-17.25 \mathrm{~T} \\
-4939.5\end{array}$ & $\begin{array}{c}+82254 \\
+35866 \\
+25855-44.631 \mathrm{~T} \\
-4906-0.975 \mathrm{~T} \\
-4808+0.2 \mathrm{~T} \\
-1389\end{array}$ \\
\hline $\begin{array}{c}\mathrm{fcc} \\
(\beta-\mathrm{Am}, \delta-\mathrm{Pu})\end{array}$ & $\begin{array}{l}\mathrm{Am}-\mathrm{U} \\
\mathrm{Am}-\mathrm{Pu} \\
\mathrm{Pu}-\mathrm{U}\end{array}$ & $\begin{array}{l}{ }^{0} L \\
{ }^{1} L \\
{ }^{0} L \\
{ }^{1} L \\
{ }^{2} L \\
{ }^{0} L \\
{ }^{1} L\end{array}$ & $\begin{array}{c}+30114 \\
-4961 \\
+1280 \\
-102.7 \\
- \\
+3600 \\
+1300\end{array}$ & $\begin{array}{c}+50000 \\
- \\
-22630+26.367 \mathrm{~T} \\
-6091 \\
0.13367 \\
+723.76 \\
-\end{array}$ & $\begin{array}{c}+54442 \\
+23338 \\
+21157-40.723 \mathrm{~T} \\
-1518-3.885 \mathrm{~T} \\
- \\
+3136 \\
-\end{array}$ \\
\hline$\alpha-\mathrm{Am}$ & $\begin{array}{l}\mathrm{Am}-\mathrm{U} \\
\mathrm{Am}-\mathrm{Pu} \\
\mathrm{Pu}-\mathrm{U}\end{array}$ & $\begin{array}{l}{ }^{0} L \\
{ }^{0} L \\
{ }^{1} L \\
{ }^{0} L\end{array}$ & $\begin{array}{l}- \\
- \\
- \\
-\end{array}$ & $\begin{array}{l}+50000 \\
+5000 \\
- \\
+10000\end{array}$ & $\begin{array}{c}- \\
+13362-22.212 \mathrm{~T} \\
+6981.4-3.298 \mathrm{~T} \\
-\end{array}$ \\
\hline$\alpha-\mathrm{U}$ & $\begin{array}{l}\mathrm{Am-U} \\
\mathrm{Am}-\mathrm{Pu} \\
\mathrm{Pu}-\mathrm{U}\end{array}$ & $\begin{array}{l}{ }^{0} L \\
{ }^{0} L \\
{ }^{0} L \\
{ }^{1} L\end{array}$ & $\begin{array}{l}- \\
- \\
- \\
-\end{array}$ & $\begin{array}{c}+50000 \\
+5000 \\
+6176.5 \\
-\end{array}$ & $\begin{array}{c}- \\
- \\
-12689+3.9 \mathrm{~T} \\
+9712-11.8 \mathrm{~T}\end{array}$ \\
\hline$\beta-\mathrm{U}$ & $\begin{array}{l}\mathrm{Am}-\mathrm{U} \\
\mathrm{Am}-\mathrm{Pu} \\
\mathrm{Pu}-\mathrm{U}\end{array}$ & $\begin{array}{l}{ }^{0} L \\
{ }^{0} L \\
{ }^{0} L\end{array}$ & $\begin{array}{l}- \\
- \\
-\end{array}$ & $\begin{array}{l}+50000 \\
+5000 \\
+5287.3 \\
\end{array}$ & $\begin{array}{c}- \\
- \\
-12577+8.9 \mathrm{~T}\end{array}$ \\
\hline$\alpha-\mathrm{Pu}$ & $\begin{array}{l}\mathrm{Am}-\mathrm{U} \\
\mathrm{Am}-\mathrm{Pu} \\
\mathrm{Pu}-\mathrm{U}\end{array}$ & $\begin{array}{l}{ }^{0} L \\
{ }^{0} L \\
{ }^{0} L\end{array}$ & $\begin{array}{l}- \\
- \\
-\end{array}$ & $\begin{array}{l}+50000 \\
+5000 \\
+5000\end{array}$ & +31 573.21 - 39.159T \\
\hline$\beta-\mathrm{Pu}$ & $\begin{array}{l}\mathrm{Am}-\mathrm{U} \\
\mathrm{Am}-\mathrm{Pu} \\
\mathrm{Pu}-\mathrm{U}\end{array}$ & $\begin{array}{l}{ }^{0} L \\
{ }^{0} L \\
{ }^{0} L\end{array}$ & $\begin{array}{l}- \\
- \\
-\end{array}$ & $\begin{array}{l}+50000 \\
+5000 \\
+5000\end{array}$ & $\begin{array}{c}+40000 \\
+20502.32-11.335 \mathrm{~T} \\
-4343\end{array}$ \\
\hline$\gamma-\mathrm{Pu}$ & $\begin{array}{l}\mathrm{Am}-\mathrm{U} \\
\mathrm{Am}-\mathrm{Pu} \\
\mathrm{Pu}-\mathrm{U}\end{array}$ & $\begin{array}{l}{ }^{0} L \\
{ }^{0} L \\
{ }^{0} L\end{array}$ & $\begin{array}{l}- \\
- \\
-\end{array}$ & $\begin{array}{l}+50000 \\
+5000 \\
+4342.7\end{array}$ & $\begin{array}{c}+40000 \\
+36659.75-43.919 \mathrm{~T} \\
+4090\end{array}$ \\
\hline$\delta^{\prime}-\mathrm{Pu}$ & $\begin{array}{l}\mathrm{Am}-\mathrm{U} \\
\mathrm{Am}-\mathrm{Pu} \\
\mathrm{Pu}-\mathrm{U}\end{array}$ & $\begin{array}{l}{ }^{0} L \\
{ }^{0} L \\
{ }^{0} L\end{array}$ & $\begin{array}{l}- \\
- \\
\end{array}$ & $\begin{array}{l}+50000 \\
+5000 \\
+495.37 \\
\end{array}$ & $\begin{array}{c}+40000 \\
+37000-44 \mathrm{~T} \\
+2411\end{array}$ \\
\hline$\zeta$ & $\begin{array}{l}\mathrm{Am}-\mathrm{U} \\
\mathrm{Am}-\mathrm{Pu} \\
\mathrm{Pu}-\mathrm{U}\end{array}$ & $\begin{array}{l}{ }^{0} L \\
{ }^{0} L \\
{ }^{0} L \\
{ }^{1} L \\
{ }^{2} L\end{array}$ & $\begin{array}{l}- \\
- \\
- \\
-\end{array}$ & $\begin{array}{c}+50000 \\
+5000 \\
-6336.9+10.446 \mathrm{~T} \\
-19997+24.65 \mathrm{~T} \\
+12364-7.8368 \mathrm{~T}\end{array}$ & $\begin{array}{c}- \\
- \\
-87904+99.2 \mathrm{~T} \\
-23547+54.6 \mathrm{~T} \\
+33907-19.9 \mathrm{~T}\end{array}$ \\
\hline$\eta$ & $\begin{array}{l}\mathrm{Am-U} \\
\mathrm{Am}-\mathrm{Pu} \\
\mathrm{Pu}-\mathrm{U}\end{array}$ & $\begin{array}{l}{ }^{0} L \\
{ }^{0} L \\
{ }^{0} L \\
{ }^{1} L\end{array}$ & $\begin{array}{l}- \\
- \\
-\end{array}$ & $\begin{array}{c}+50000 \\
+5000 \\
+4049.1-1.5232 \mathrm{~T} \\
-617.36-3.4139 \mathrm{~T}\end{array}$ & $\begin{array}{c}- \\
- \\
-12970+8.3 \mathrm{~T} \\
+2690-3.5 \mathrm{~T}\end{array}$ \\
\hline
\end{tabular}




\section{Figure Captions}

Figure 1. Predicted (a-c) Am-U, Am-Pu and Pu-U phase diagrams, and (d) isothermal section of the $\mathrm{Pu}-\mathrm{U}-\mathrm{Am}$ system at $927^{\circ} \mathrm{C}(1200 \mathrm{~K})$ using the Brewer valence bond model [3], according to the results of Ogawa [2]. (Reproduced with the agreement of T. Ogawa and reprinted with permission of Elsevier via Copyright Clearance Center)

${ }_{620} \quad$ Figure 2. (Color online) Predicted (a-c) Am-U, Am-Pu and $\mathrm{Pu}-\mathrm{U}$ phase diagrams, and (d) isothermal section of the Pu-U-Am system at $927^{\circ} \mathrm{C}(1200 \mathrm{~K})$ according to the CALPHAD thermodynamic database published by Kurata $[8,9]$.

Figure 3. (Color online) Ab initio informed CALPHAD assessment of the $\mathrm{Pu}-\mathrm{U}$

${ }_{625}$ system [19]. The symbols (]$\left.,,, \diamond, \bigcirc\right)$ represent the experimental data taken from $[14,15,16,17,18]$, respectively.

Figure 4. (Color online) Ab initio informed CALPHAD assessment of the Am-Pu system from Turchi's study [20]. (a) Final assessment of the Am-Pu system with corresponding interaction parameters given in Table 3. (b) Assessed Am-Pu phase diagram by assuming a less stable bcc solid solution (see Section 4.1).

Figure 5. (a) Heats of formation (symbols, in $\mathrm{kJ} / \mathrm{mol}$ ) of the bcc phase for the Am-U [34], Am-Np [34], Am-Pu [33] and Pu-U [32] alloys and of the fcc phase for Am-U 635 (present study) and Am-Pu [20] systems at $\mathrm{T}=0 \mathrm{~K}$, based on the FR-EMTO-CPA method. (b) Metastable miscibility gaps calculated using Eq. 11 and based only on the T-independent RK interaction parameters determined from (a) (Eq. 16-19). The T-dependent RK interaction parameters are not considered here.

Figure 6. (Color online) Ab initio informed CALPHAD re-assessment of the Am-U system. 
Figure 7. (Color online) Predicted isothermal sections of the Pu-U-Am system calculated from the Kurata's database [8, 9]. The red circles represent the

${ }_{645} \mathrm{Pu}_{.10} \mathrm{U}_{.86} \mathrm{Am}_{.04}$ composition.

Figure 8. (Color online) Predicted isothermal sections, based on the present assessment, of the $\mathrm{Pu}-\mathrm{U}-\mathrm{Am}$ phase diagram. The red circles represent the $\mathrm{Pu}_{.10} \mathrm{U}_{.86} \mathrm{Am}_{.04}$ composition.

650

Figure 9. (Color online) Predicted isothermal sections of the Pu-U-Am phase diagram based on the present assessment with a less stable bcc solid solution for the Am-Pu system (see Section 4.1). Only the isotherms that differ from Fig. 8 are presented.

655 Figure 10. (Color online) Calculated isopleth sections based on the present assessment for the following compositions: (a) $\mathrm{Pu}_{.95} \mathrm{U}_{.05} \rightarrow \mathrm{Pu}_{.85} \mathrm{U}_{.05} \mathrm{Am}_{.10}$ (5 at.\% $\mathrm{U}$ isopleth), (b) $\mathrm{Pu}_{.22} \mathrm{U}_{.78} \rightarrow \mathrm{Pu}_{.12} \mathrm{U}_{.78} \mathrm{Am}_{.10}$ (78 at.\% $\mathrm{U}$ isopleth).

Figure 11. (Color online) Calculated property diagrams based on the present assessment for the following systems: (a) $\mathrm{Pu}_{.95} \mathrm{U}_{.05}$, (b) $\mathrm{Pu}_{.90} \mathrm{U}_{.05} \mathrm{Am}_{.05}$, (c) $\mathrm{Pu}_{.85} \mathrm{U}_{.05} \mathrm{Am}_{.10}$, (d) $\mathrm{Pu}_{.22} \mathrm{U}_{.78}$, (e) $\mathrm{Pu}_{.17} \mathrm{U}_{.78} \mathrm{Am}_{.05}$, (f) $\mathrm{Pu}_{.12} \mathrm{U}_{.78} \mathrm{Am}_{.10}$. 
Figure 1
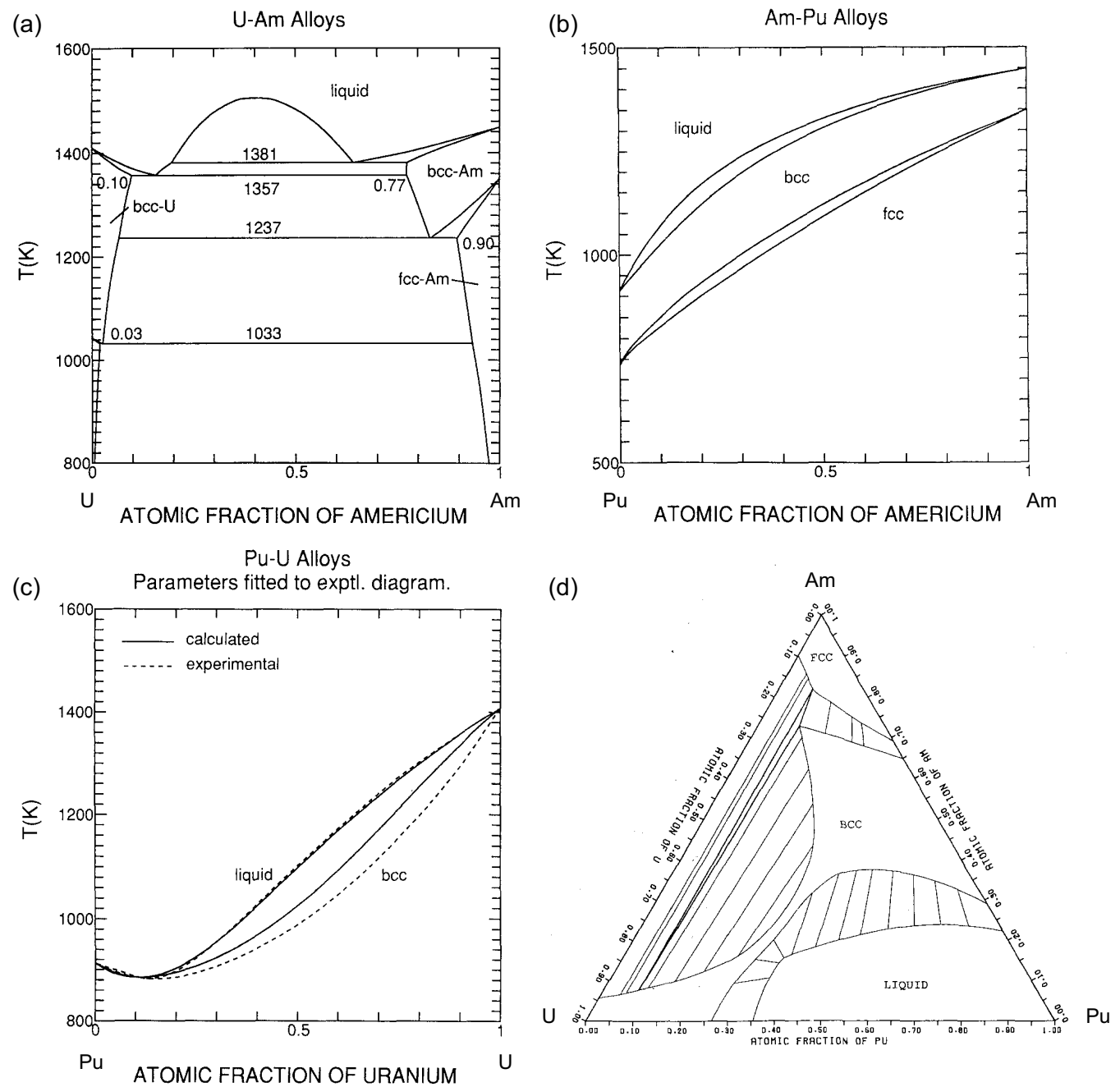
(a)

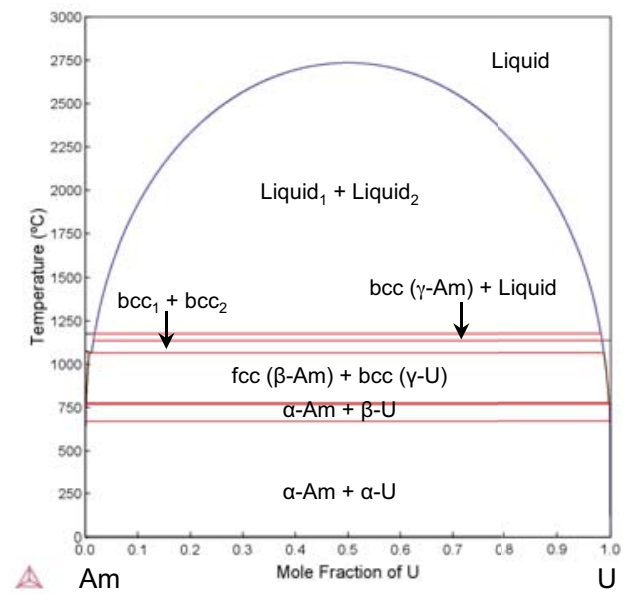

(c)

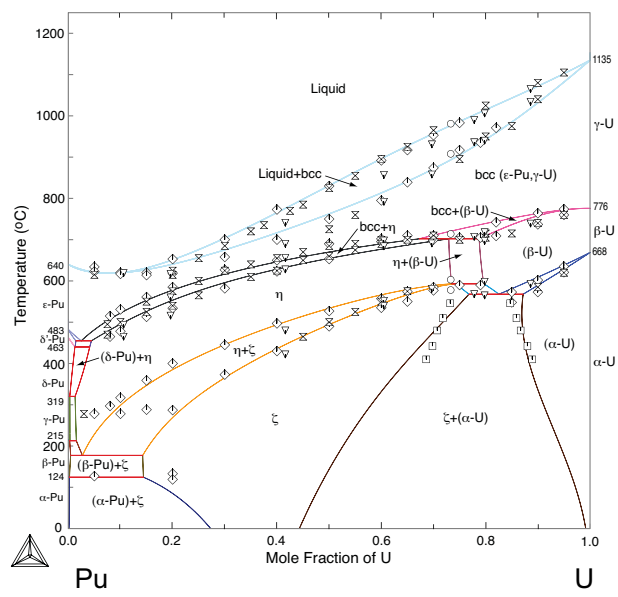

(b)

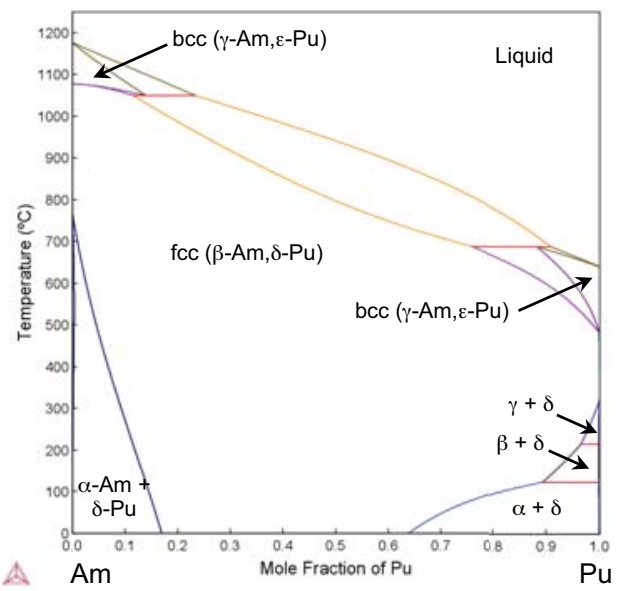

(d)

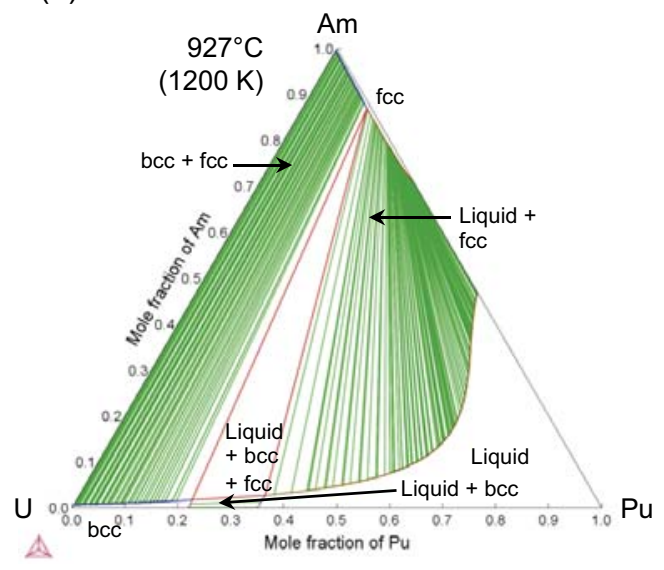




\section{Figure 3}

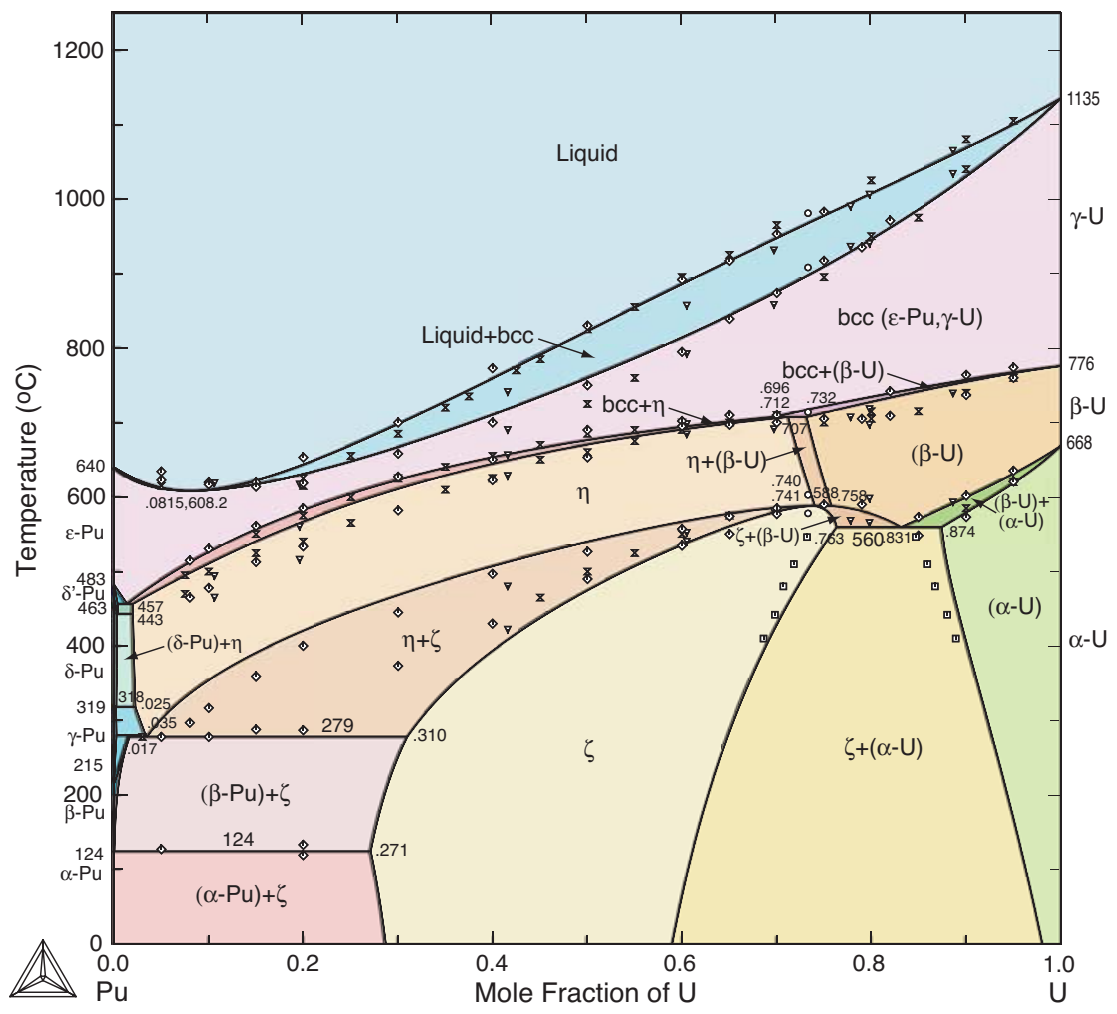


Figure 4
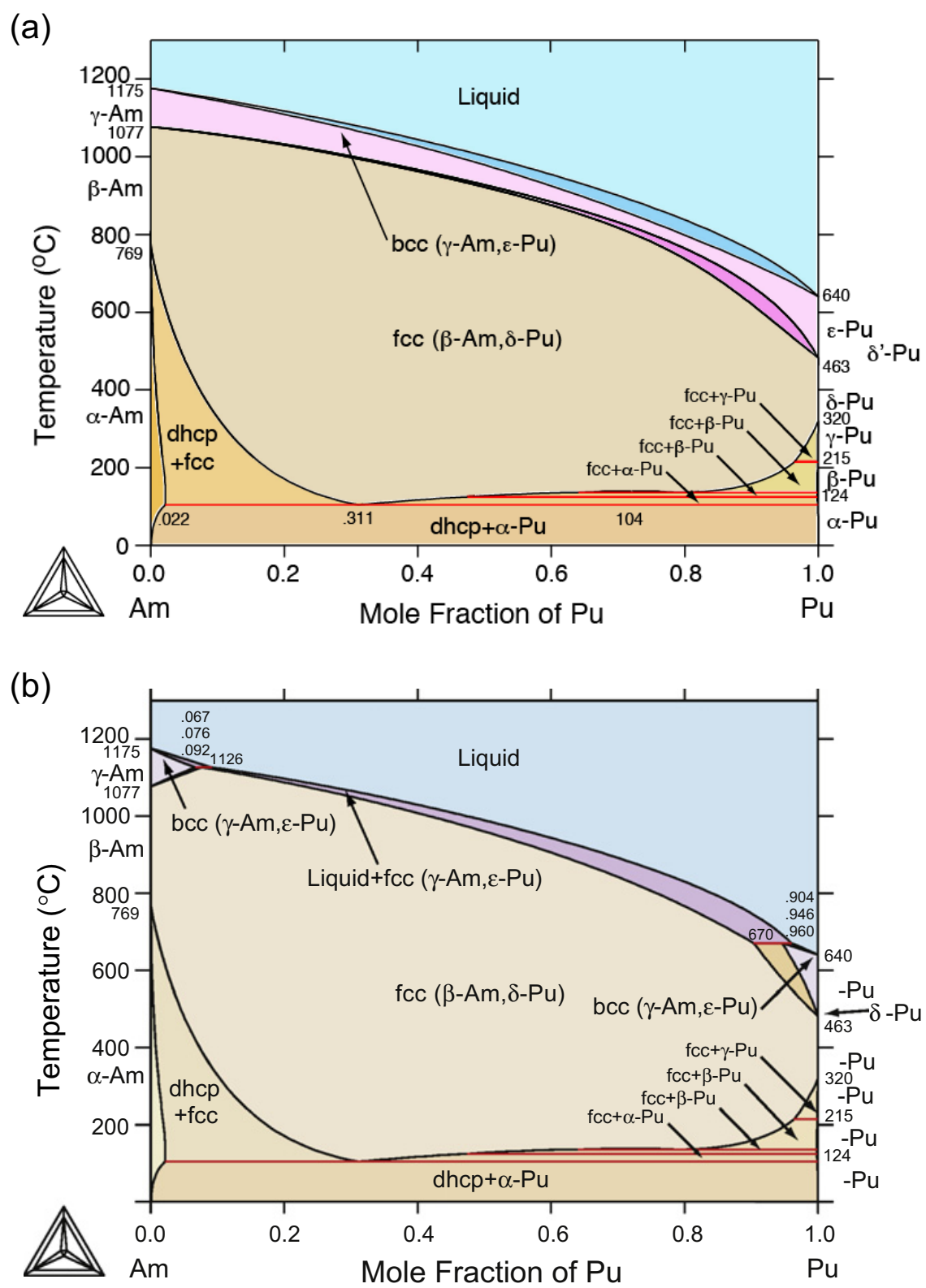
Figure 5

(a)

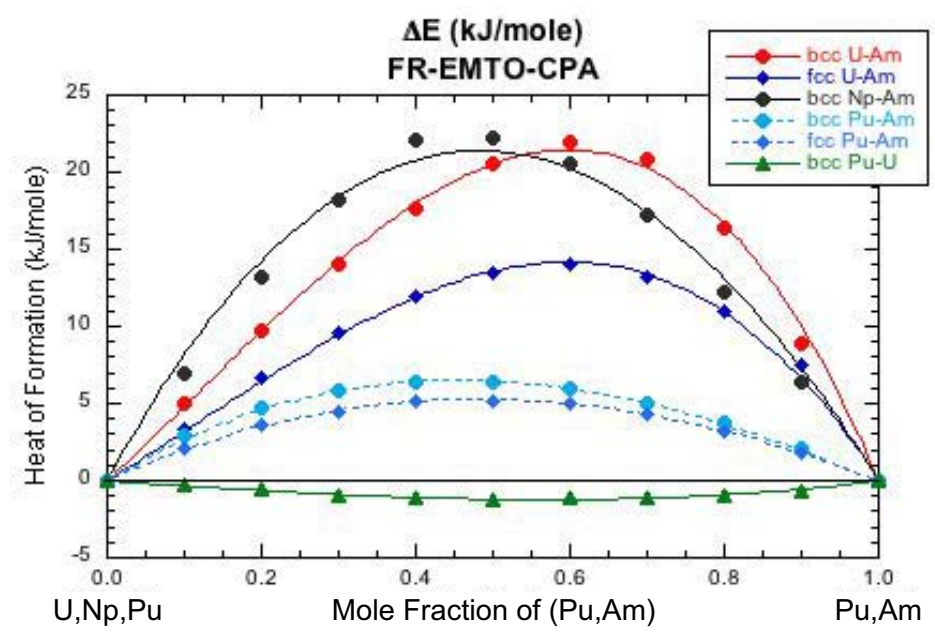

(b)

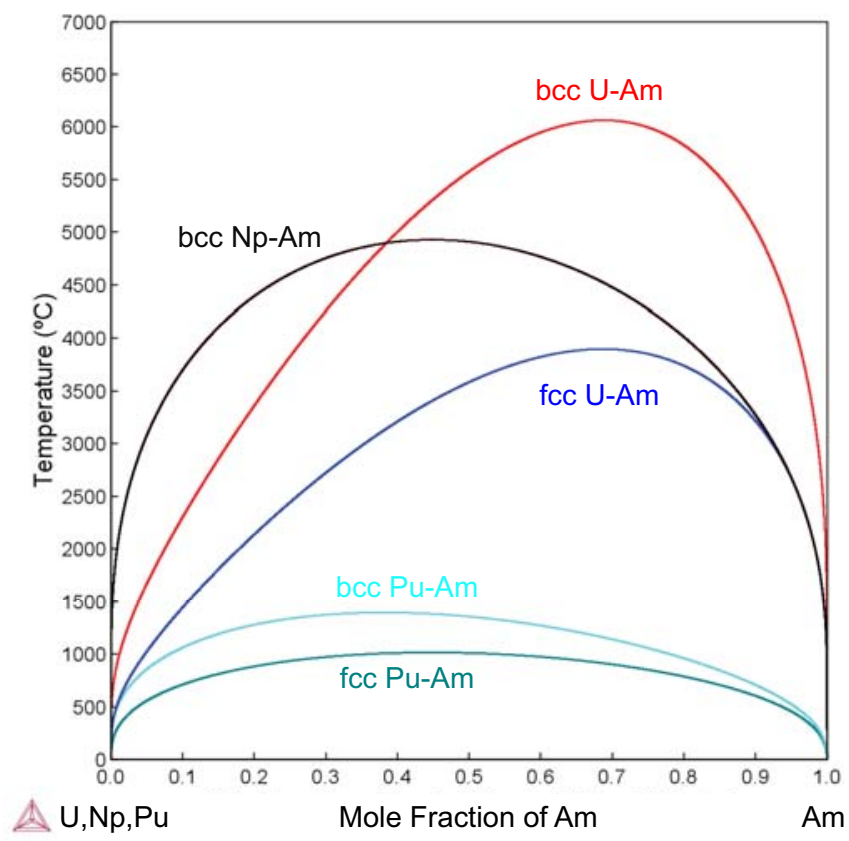


Figure 6

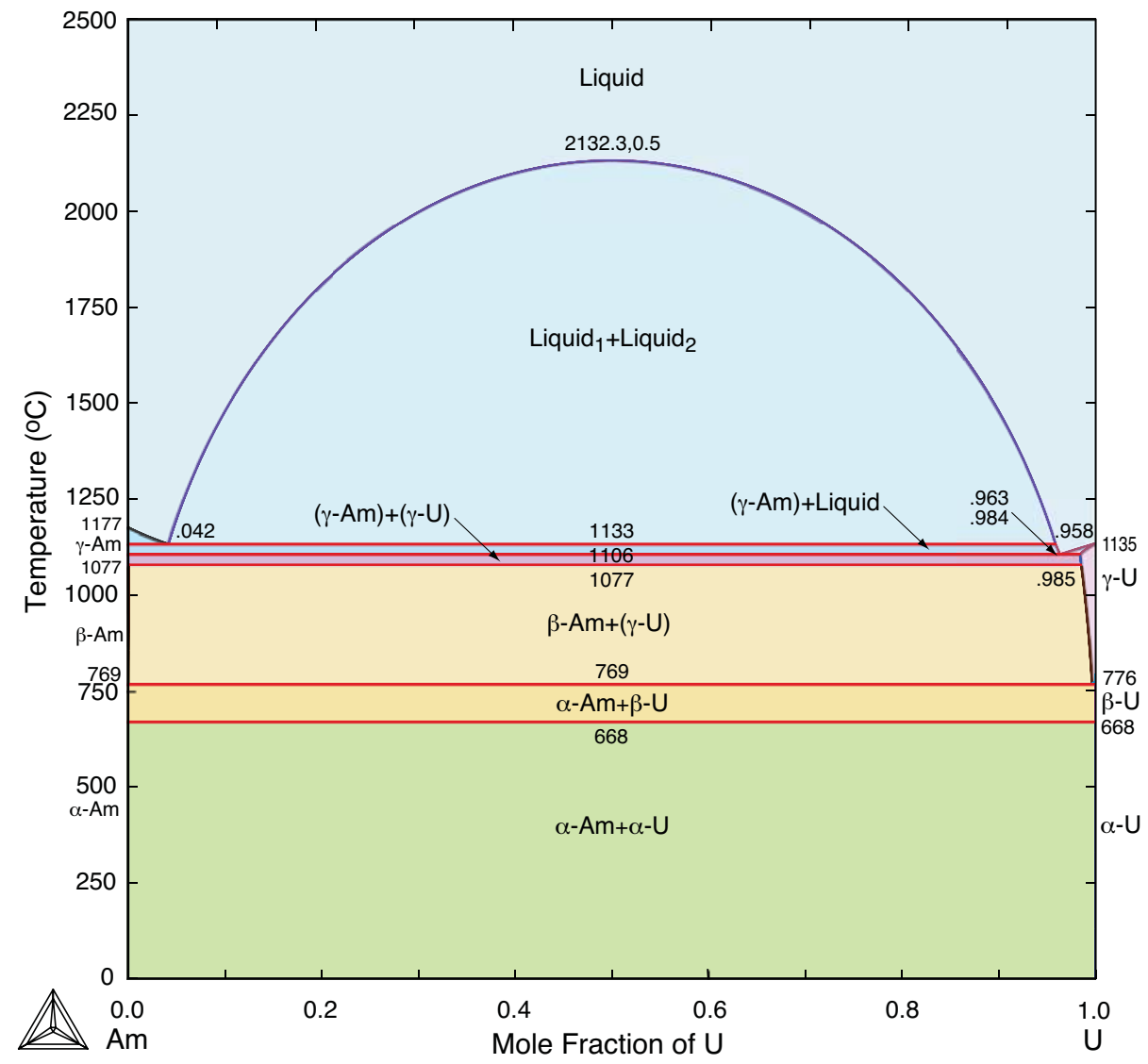


Figure 7
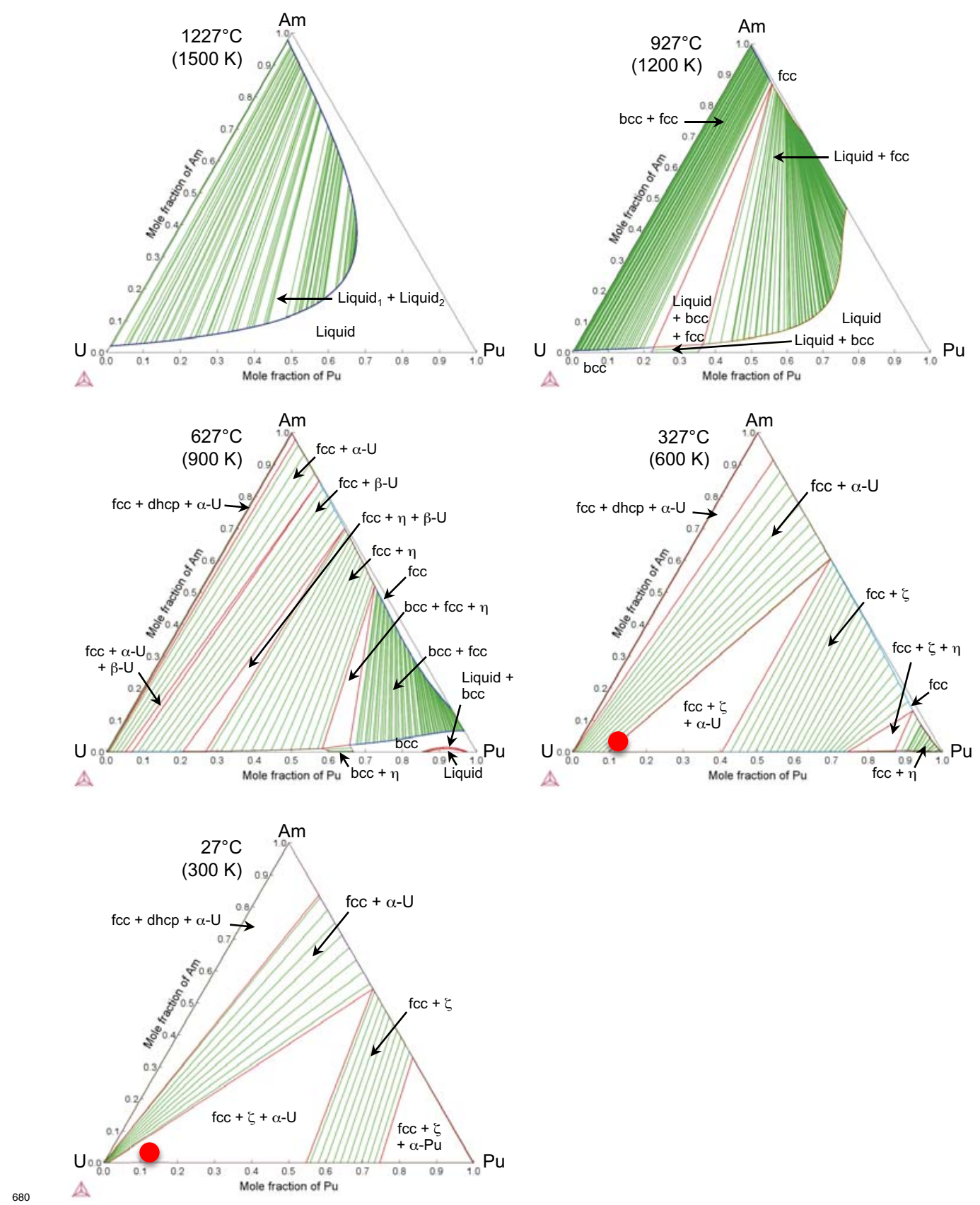
Figure 8
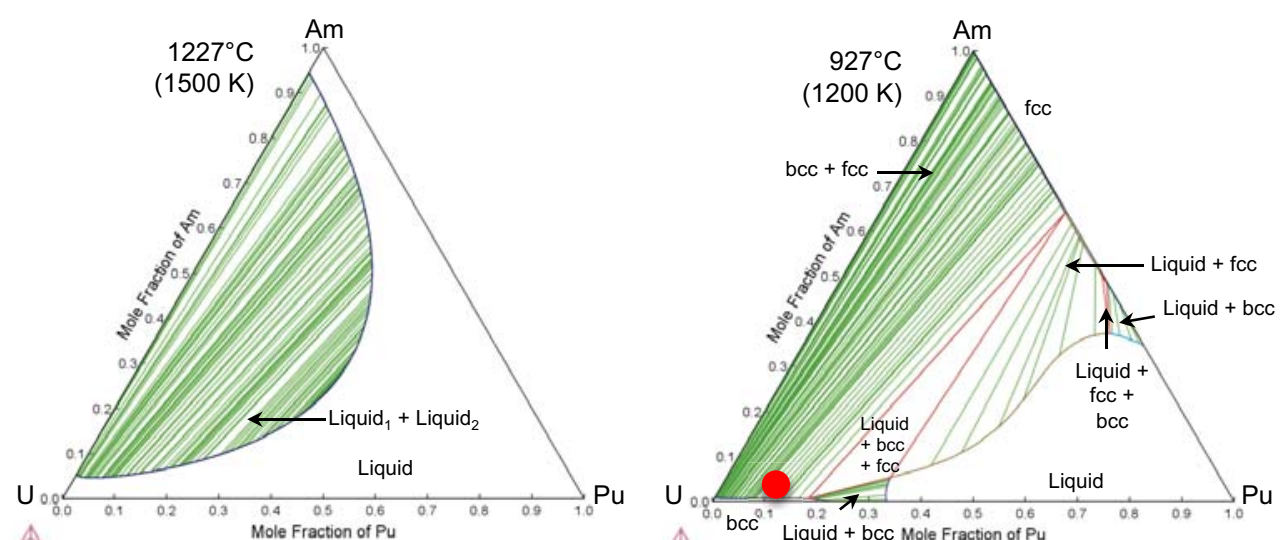

$\Delta$

A bcc Liquid + bcc Mole Fraction of $\mathrm{P}$
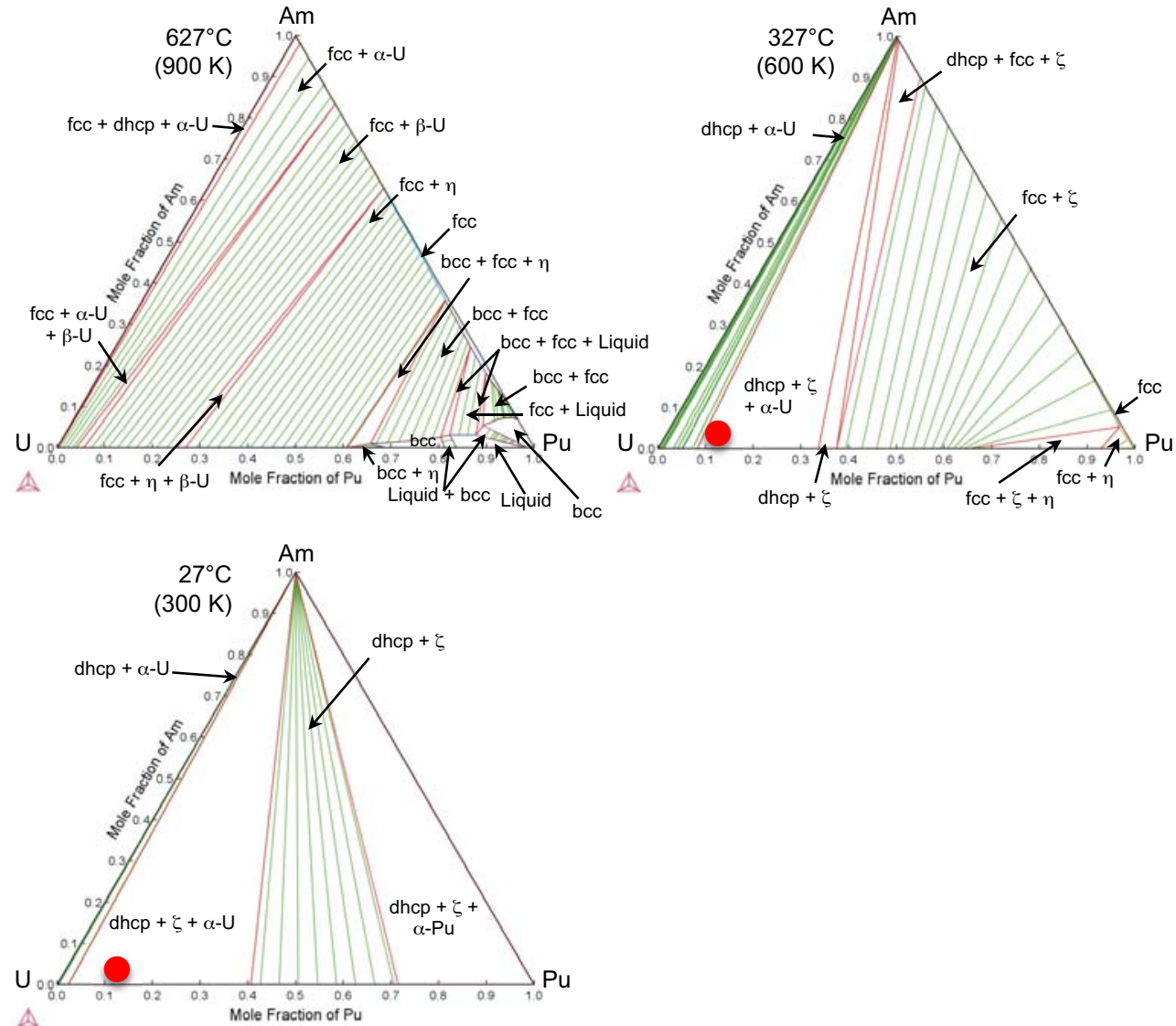
Figure 9

685
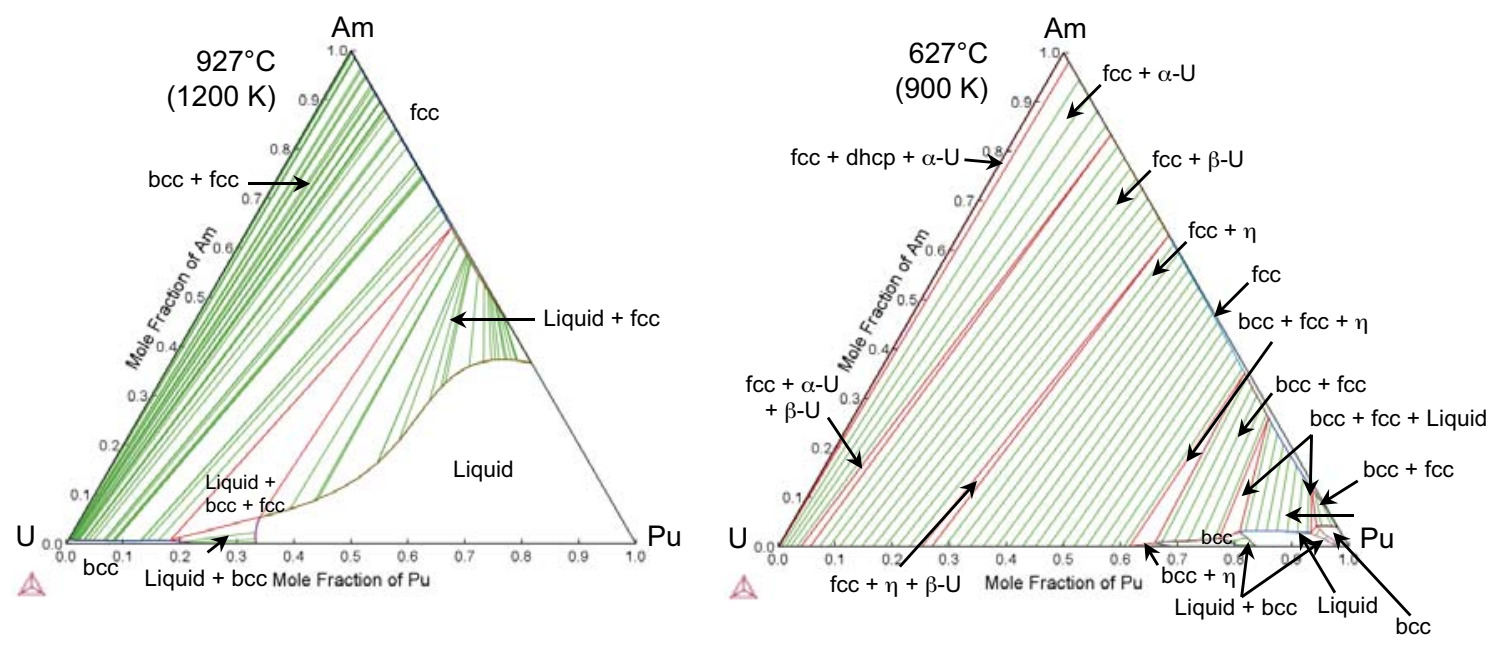


\section{Figure 10}

(a)

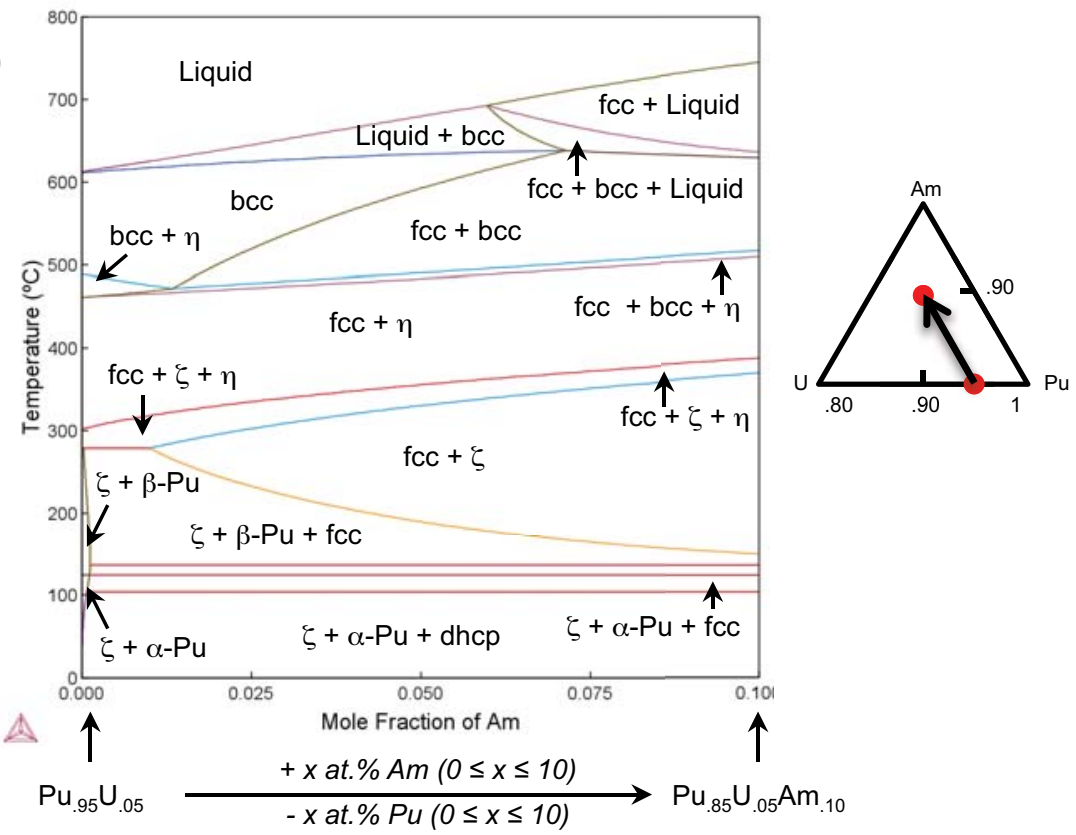

(b)

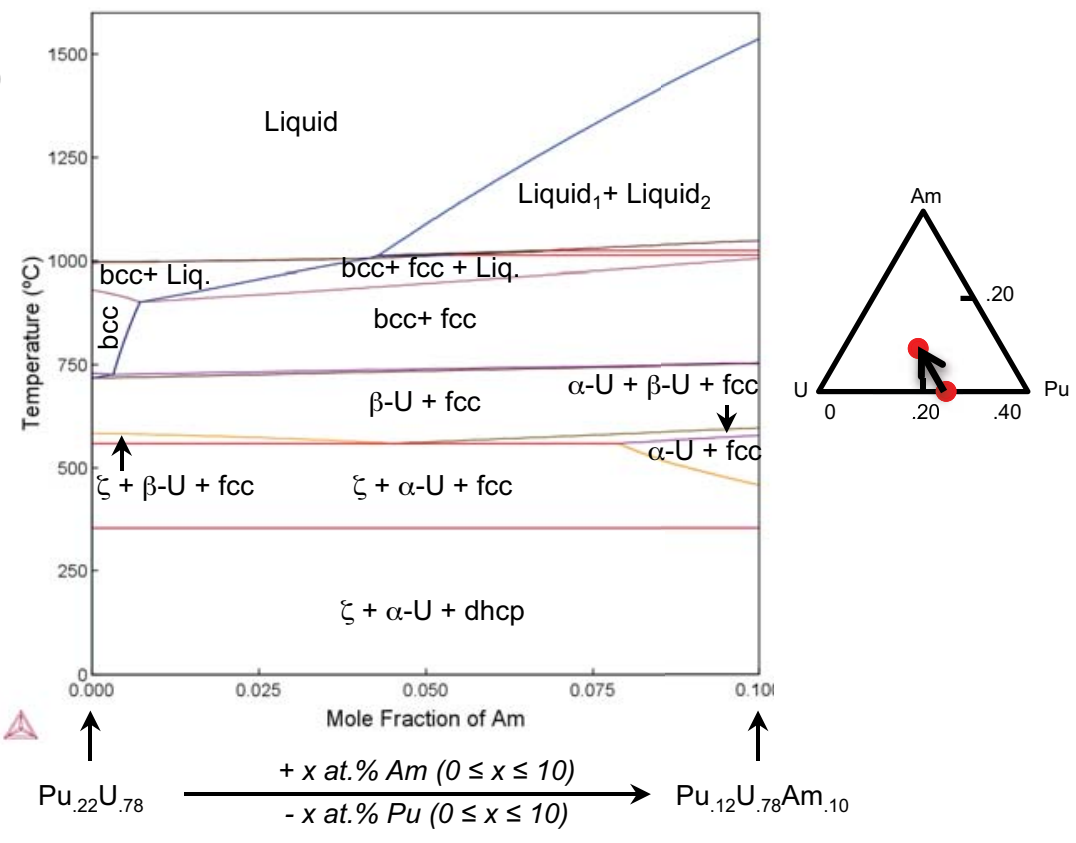




\section{Figure 11}

690

(a)

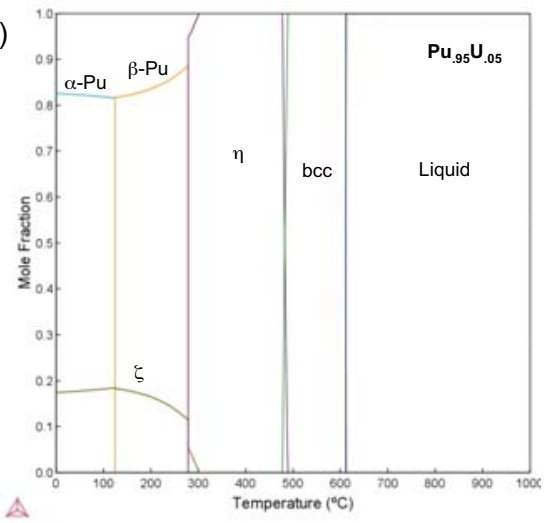

(b)

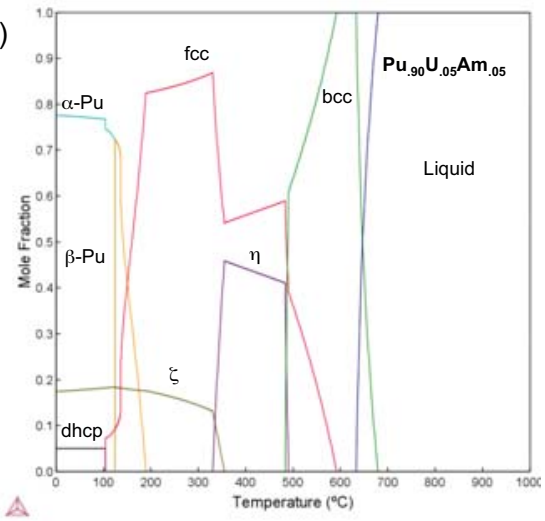

(c)

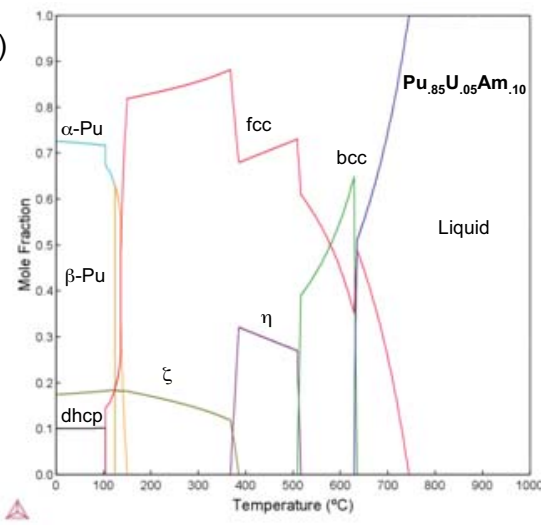

(d)

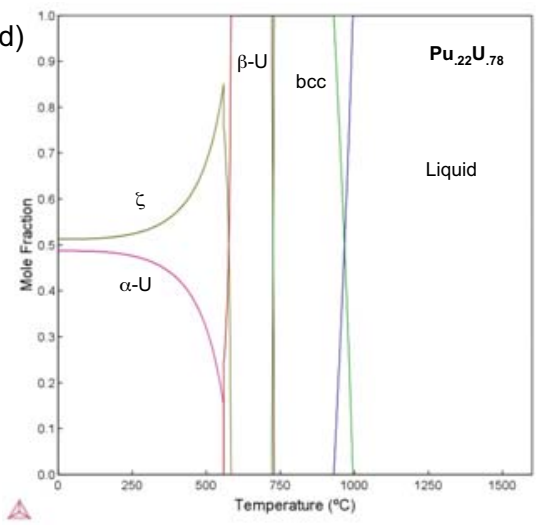

(d)
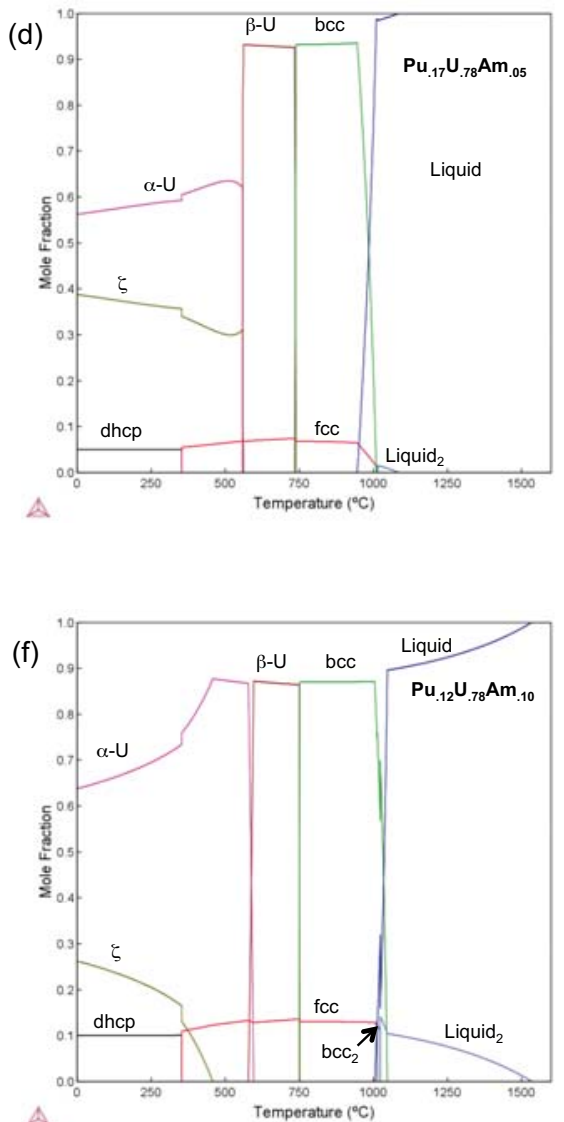


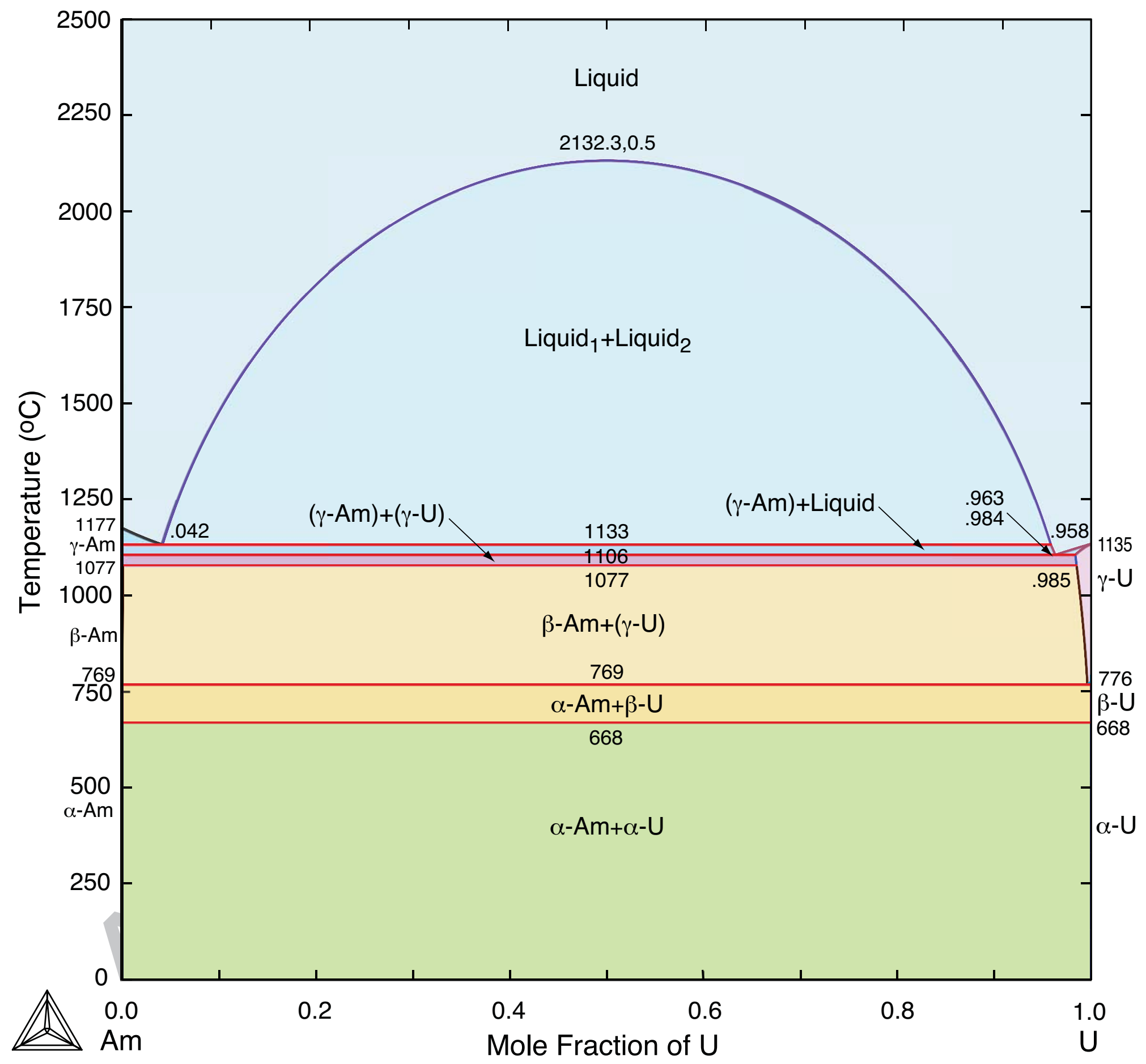

